\title{
ARQUEOLOGÍA DEL PAISAJE: HISTORIA, PROBLEMAS Y PERSPECTIVAS
}

\author{
POR \\ ALMUDENA OREJAS \\ Depto. de Historia Antigua y Arqueología. CSIC. CEH.
}

\begin{abstract}
RESUMEN
La Arqueología del paisaje tiene poco más de treinta años, y el nacimiento de un auténtico interés por el paisaje como objeto de estudio en esta ciencia poco más de quince. Sin embargo, en su gestación han intervenido prácticamente todas las tendencias que han conformado la evolución de la Arqueología en la última centuria.

Su aceptación encuentra numerosos obstáculos, nacidos tanto de reticencias y escepticismos, como de problemas surgidos de su indefinición y de unos objetivos y métodos aún poco sólidos. No obstante, la reciente puesta en marcha de una reflexión teórica y metodológica y de proyectos de investigación concebidos en esa dirección permiten perfilar algunos de sus rasgos mas carácterísticos, sus perspectivas y formas de trabajo.

Por último, el desarrollo de la Arqueología del paisaje y el interés que suscita en diferentes medios está estrechamente vinculado a unas nuevas condiciones y exigencias sociales ligadas a los complejos problemas de planificación y gestión del espacio, que demandan una reunión del ámbito científico y el social, progresivamente disociados.
\end{abstract}

\section{SUMMARY}

Landscape Archeology is hardly thirty years old, and the birth of a real interest in landscape as an object of study in this science occurred little more than fifteen years ago; even so, practically all the trends that have shaped the evolution of archeology in the last century are present in its gestation.

Its acceptance has been held back by prejudices born out of reticence and scepticism, as well as by the problems of its lack of definition and still no very solid objectives and methods. The recent beginnins, however, of a review of its theoreti al and methodological foundations and of research projects in this direction will provide a profile of its most characteristics features, perspectives and work methods.

Lastly, the development of landscape archeology and the interest it creates in different fields is closely linked to the new social conditions and demands coming from the complex problems of planning and management of space, which reguire a drawing together of the increasinSly disassociated scientific and social spheres. 
Desde que en 1957 Bradford publicara su Ancient Landcapes el término paisaje ha ido apareciendo sucesivamente en abundantes trabajos relacionados con la Arqueología, y no siempre con el mismo sentido. Hoy, hablar de Arqueología del paisaje o de paisaje arqueológico comienza a resultar familiar, aunque en raras ocasiones el uso de estas expresiones va acompañado de una reflexión adecuada sobre su sentido, métodos y objetivos, y sobre el contexto social e ideológico en que se inscribe este interés por el tema.

La aparición de una Arqueología del paisaje con una entidad propia es reciente y, en cierta medida, espontánea, surgida tanto del ritmo de la evolución de la ciencia como de la aparición de unos problemas sociales nuevos que han suscitado respuestas desde diversoso ámbitos (científico, político, etc.). Su nacimiento, a su vez, genera una serie de dificultades que van desde la creación o adopción de una terminología al cuestionamiento de su entidad científica. Una revisión de algunas aportaciones de las corrientes de mayor incidencia en la Arqueología de nuestro siglo pueden ayudarnos a precisar qué contribuye a la configuración de paisaje como tema de estudio, cómo desde diversos enfoques y paises toman forma iniciativas e intereses que confluyen en objetivos comunes, enriquecidos unas veces por tradiciones y puntos de vista dispares, y en otras ocasiones, pese a los muchos puntos en común, dándose la espalda.

Desde esta perspectiva, se podrán apuntar algunos de los rasgos esenciales de estos estudios, sus pretensiones y formas de trabajo específicas, así como su directa vinculación con la reivindicación del patrimonio natural y social.

La forma de afrontar un tema amplio y complejo como este - no ya por su historia dentro de la Arqueología, sino por su estrecha relación con otras ciencias, movimientos sociales, políticos, presiones económicas, etc., y por su voluntad integradora-, ha sido necesariamente selectiva: no están citados todos los que han contribuido o toman parte en su formación, sin embargo, al menos si se pretende representar las líneas de fuerza fundamentales y algunas aportaciones quizás menos evidentes. Si algo caracteriza a la Arqueología del paisaje, por su naturaleza y objeto de estudio, es el dinamismo y la flexibilidad que garantizan una constante discusión, un avance multidireccional, abierto e integrador.

\section{EL TÉRMINO «PAISAJE»: ENTRE LA AMBIGÜEDAD Y LA GLOBALIDAD}

En la Arqueología de los últimos veinticinco años se ha difundido un vocabulario nuevo, en una pequeña parte acuñado dentro del mundo de la Arqueología, y en una importante proporción tomado de otras ciencias: términos como espacio (análisis espacial, arqueología espacial), territorio (estudios territoriales), medio, medioambiente, entorno, relaciones ecológicas, nicho ecológico, arqueología del paisaje, arqueología aérea, y un largo etcétera, han pasado a formar parte del lenguaje de historiadores y arqueólogos. Sin embargo, su adopción en ocasiones ha sido el resultado de la necesidad de cubrir vacíos apresuradamente, sin acompañarse de una adecuada reflexión a propósito del sentido, uso y connotaciones del vocablo aceptado, por ello, llega un momento en que se hace necesaria una seria revisión y replanteamiento de los significados otorgados, los tratamientos específicos por parte de autores y equipos de trabajo y los matices de cada lengua, así como las propuestas lanzadas como alternativas.

El término paisaje, al que ahora nos referimos, es en este sentido especialmente conflictivo: por una parte, los usos reales dados a la palabra rebasan, con mucho, su significado estricto, y, 
por otra, siempre ha acusado una falta de precisión y, por ello mismo, una fuerte polisemia. Es tan impreciso como fácil de comprender y esto ha sido el origen del debate generado en torno a su uso científico y de las dificultades para encontrar un sustituto sin perder riqueza semántica y claridad. Derivadas de él se han generado expresiones como arqueología del paisaje, paisaje arqueológico, lectura histórica del paisaje que han conservado esta indefinición.

La imprecisión del vocablo nace de un significado en origen muy restringido y que se ha ido ampliando por extensión a realidades próximas a la primera. No obstante, esta evolución del vocablo presenta un doble problema: por una parte no ha ido teniendo un reflejo inmediato en las definiciones «oficiales» del mismo - retraso aún hoy constatable- y, en segundo lugar, no ha seguido el mismo ritmo en todas las lenguas, de forma que los términos que se consideran equivalentes no se refieren exactamente a las mismas realidades. Un rápido rastreo por algunos diccionarios de diversos momentos y lenguas puede ayudarnos a precisar algo más esta cuestión.

El primer problema que presenta el uso del término español paisaje en Arqueología, como en cualquier otra ciencia, procede de la ambiguiedad que rodea al vocablo debido a su tradicional uso: efectivamente, aún hoy, la primera, y con frecuencia única acepción otorgada al término en los diccionarios españoles es la de «representación artística (casi siempre pictórica) de una espacio». Esto ha hecho que el término sea indisociable de una visión subjetiva, plasmada de una forma también subjetiva.

Partiendo de algunas definiciones podemos perfilar la trayectoria desde esta acepción primitva:

TERREROS (1788): paisaje, en la pintura, V. país, y Palomino que lo toma por un pedazo de país, paisaje, la vista o aspecto de algún país y en la pintura las arboledas y casas de campo; país, se dice de las diversas partes, regiones, provincias y parajes del Universo; que se ve de una mirada, de una ojeada.

RODRIGUEZ NAVA (1907): paisaje, cuadro que representa un país o campo en la pintura. // Terreno en que se fija la atención desde el punto de vista artístico.

MARIA MOLINER (1971): paisaje, 1) Extensión de campo que se ve desde un sitio. El campo considerado como espectáculo. 2) Pintura que representa una extensión de campo. 3) Papel o tela, generalmente decorada, que se extiende sobre las varillas del abanico por la parte por donde se separan. 4) Se emplea en geografía con el significado de "configuración del terreno" ».

LAROUSSE (1981): paisaje, extensión de terreno vista desde un lugar determinado. // Tela, papel $\mathrm{u}$ otro material que recubre las varillas del abanico.

-Geogr: área de dimensiones muy variables caracterizada por rasgos geomorfológicos, climáticos, de hábitat, etc., suficientes para diferenciarla: paisaje desértico, paisaje industrial.

-Art: pintura, grabado o dibujo en el que el tema principal es la representación de un lugar natural o urbano. // Parte del cuadro que forma una decoración detrás de los personajes que ocupan el primer plano.

REAL ACADEMIA (1984): paisaje, país, pintura, dibujo // 2. Porción de terreno considerada en su aspecto artístico.

Comprobamos como esta primera acepción, reducida al mundo de la expresión artística, se ve ampliada en algunas definiciones, pasando a referirse a un espacio contemplado por un observador desde un punto: así, la primera acepción recogida por María Moliner plantea este aspecto e identifica este espacio con el campo (entendido como lugar desprovisto de ciudades) y, por lo tanto, manteniendo una visión típica de la apreciación estética. La primera acepción 
de la Enciclipedia Larousse se refiere igualmente a esta acepción del término, relegando la tradicional a un uso específico en el terreno del arte.

La segunda extensión de vocablo se refiere a su relación con la Geografía. La asunción del paisaje como una realidad geográfica se debe remontar al final del siglo pasado, $y$, en especial al desarrollo del enfoque regional en el ámbito francés; en ella la consideración del paisaje como un área que ve un espectador, sirve para pasar a la idea de aspecto externo del terreno (acepción cuarta de María Moliner y apartado dedicado a la Geografía en Larousse).

En la misma dirección se entiende el término italiano equivalente paessagio ${ }^{1}$, tradicionalmente ligado también a la visión estética. No ocurre esto en otros idiomas: el término anglosajón landscape es enormemente rico, en él se tienen en cuenta tanto el medio natural, como las actividades agrarias e industriales y la implantación del hábitat ${ }^{2}$. Esta amplitud semántica del término ha sido acentuada desde la geografía americana al incluir en ella todos los aspectos relacionados con la percepción ${ }^{3}$. El resultado es que landscape responde a la acepción más laxa, simple y abierta del paisaje: esto permitirá, como veremos, que expresiones como landscape archaeology o cultural lanscape nazcan con un sentido dilatado, abarcando campo (country-side), ciudades (towns) y hábitat rural (villages).

Igualmente rico resulta el vocablo francés paysage, ya en el Diccionario de Furetière, de finales del siglo XVII, aparece definido, sin limitarse a su consideración como género pictórico como «aspect d'un pays, le territoire qui s'étend jusqu'où la veuë peut porter. Les bois, les collines et les rivières sont les beaux paysages ${ }^{4}$.

Sin embargo, revisando las diversas interpretaciones del término, destaca la existencia, en todos los casos, de una vinculación unánime entre el paisaje y la apreciación sensorial (casi exclusivamente visual): de esto se han derivado los tres rasgos distintivos del vocablo, causantes del debate en torno a su uso científico, la subjetividad y la globalidad. Ante ellas las posturas han ido desde el rechazo explícito o tácito a su aceptación sin reservas, pasando por diversas propuestas de sustitución con escaso éxito. Como veremos más adelante historiadores y arqueólogos no han quedado al margen de este debate.

Podemos afirmar que esta laxitud en las definiciones y usos del término ha permitido las distintas versiones sobre el paisaje que, esquematizado, se articulan sobre dos posturas: el

' En la Enciclopedia Italiana (1949) paessagio se define como sigue: «si chiama pessagio in arte un dipinto che a per oggetto gli aspetti campestri, la natura...»

2 En el Collins English Dictionary (1984) la primera acepción del término landscape es «an extensive area of scenary as viewed from a single aspect: slageaps dominate the landscape». El término se completa con el más específico de townscape y el de country-side: «a territory distingued by the people, culture, language, geography, etc.». El término, acuñado también dentro del ámbito pictórico, aparece ya atestiguado en el siglo XVII referido a una porción de tierra vista desde un punto y en la centuria siguiente referida a descripciones y visiones de conjunto (desde arriba) de la misma (The Oxford Universal Dictionary Illustrated, 1, ed. 1973 (1. a ed. 1933).

${ }^{3}$ Nos referimos a los geógrafos que desde los primeros cincuenta formaron la llamada Escuela de Berkeley, en torno a J. B. Jackson y la revista Landscape.

4 En la misma dirección los diccionarios más recientes definen paysage como: «étendue de pays qui présente une vue d'ensemble: admirer le paysage» (Petit Larousse, 1974); «partie d'un pays que la nature présente à un observateur» (Robert, 1977); «portion d'espace analysée visuellement» (Dictionaire Géographique, 1974). 
paisaje considerado exclusivamente como la superficie visible, susceptible de contemplación estética, o como una realidad compleja, en la que se manifiestan interrelaciones entre elementos de diversa índole.

Esta bipolarización se complica al hacer entrar en el juego un segundo punto de vista: la consideración de la presencia o ausencia de hombre en el paisaje, que ha llevado a una, ya tradicional, oposición entre "paisaje natural» y «paisaje humanizado» —que a su vez esconde la oposición paisaje condicionado/condicionante- Tras la acepción artística del vocablo, es su carácter natural el que aparece, por lo general, subrayado en las diversas definiciones, fruto, como veremos, de su empleo entre geólogos, geomorfólogos y geógrafos físicos ${ }^{5}$.

Al margen del uso coloquial — cuya facilidad de comprensión y globalidad lo hacen insustituible, tendremos que tener en cuenta dos fenómenos paralelos que progresivamente van perfilando las diferentes interpretaciones y aplicaciones: por una parte, las diversas realidades que expresa el término de acuerdo con el ángulo de visión adoptado desde cada una de las disciplinas, y, en segundo lugar, la aparición de diversos adjetivos yuxtapuestos al vocablo y que tienden a delimitar su significado, algunos de ellos ya admitidos de forma general.

\section{El paisaje de las diversas ciencias}

De acuerdo con las definiciones que hemos presentado más arriba el "primer paisaje», cronológicamente, fue el paisaje de los artistas: de él se deriva la asociación del término a la contemplación visual y, por lo tanto, su carácter intrínsecamente subjetivo. Esta concepción es la que ha generado la identificación del paisaje con un espacio idílico natural o rural, que impregna el uso coloquial del vocablo.

El paisaje se convirtió por vez primera en objeto de estudio de mano de los geólogos, geomorfólogos y de la Geografía física que han mantenido sobre él un «monopolio» hasta fechas muy recientes: a ellos se les ha acusado de empobrecer el término limitándolo a la descripción de los fenómenos estudiados por estas ciencias, de ser causantes del peso de «lo natural» en el paisaje, desprovisto de la presencia humana: las prácticas agrícolas o industriales, los hábitats e incluso la vegetación, no hacían sino enturbiar la visión de estos procesos geológicos y sus resultados. Surge una tradicional vinculación del páisaje a las llamadas «ciencias de la Tierra».

La primera reivindicación de un uso menos restringido del vocablo llegó de manos de los geógrafos del «regionalismo» surgido a finales del siglo pasado en Francia, aunque no llegaron a precisar su sentido, y, más recientemente, de la Geografía agraria: de una forma poco concreta se hacía entrar en el paisaje, convertido en objeto de estudio, la actividad humana en sus diversas facetas, pero básicamente de la agricultura (el paisaje humanizado se identifica con el paisaje agrario). A ellos, y a los historiadores (casi exclusivamente medievalistas) que se ocuparon del mundo rural en la década de los treinta, debemos la primera reivindicación del término desde otro ángulo, impregnado de un afán por conseguir una visión de conjunto

5 Como ejemplo sirven estas dos acepciones de dos diccionarios franceses, el de J. Tricart (1979): "estudio integrado del medio natural, traducción espacial concreta de un ecosistema», y de G. Rougerie (1977), que margina la parte «demasiado humanizada de la biosfera». 
que permitiese ligar la actividad humana — trabajo, elementos jurídicos, sociales...- y las posibilidades u obstáculos que presenta el medio.

En ocasiones, esta confusa reivindicación aparece muy ligada a una contemplación estética, lírica del paisaje que lleva a la creación de tópicos, como la perennidad del paisaje fruto de la «sabiduría popular». Sin embargo, ese paisaje agrario no ha sido discutido, ni precisado: el riesgo inminente era caer ẹn formalismos, localismos y descriptivismos que, efectivamente, generaron una enorme producción de trabajos de Geografía e Historia herederos de esta línea.

Habrá que esperar a los años cincuenta para que arqueólogos e historiadores de la Prehistoria y del mundo antiguo se interesen por él, aún sin un planteamiento claro, casi intuitivo, fruto de las nuevas posibilidades técnicas (fotografía aérea, cartografía, palinología, etc.), de la evolución interna de las ciencias y de las necesidades a las que ésta empezaba a responder (protección de patrimonio, realización de cartas arqueológicas, etc.).

El término se ha cargado de nuevos significados en nuestros días: el paisaje ha pasado de ser algo idílico, artístico a ser considerado como un bien de consumo limitado y que, por lo tanto exige un control y salvaguarda: es lo que podríamos denominar el paisaje de las planificaciones y de la política. Esto no es nuevo: desde el mundo griego la representación y descripción del espacio se ha desarrollado en función de las necesidades de control del mismo: rutas de navegación, catastros, inventarios de bienes... Sin embargo, en el presente, la situación se ha visto agravada por la demanda de espacio y la escasez de recursos que han generado una reacción en diversos sentidos y, en general, un interés por el entorno que va desde los movimientos ecologistas a la especulación del suelo urbano o las concentraciones agrarias.

\section{El paisaje y los paisajes}

Como consecuencia de este carácter multiforme y de la ambigüedad creciente del término (lo que Bertrand denominó «la transparencia del paisaje»), se ha ido haciendo necesaria, progresivamente, la caracterización del paisaje, precisando o limitando su significado mediante adjetivaciones que permiten definir su morfología, función o connotaciones conceptuales, y, así, considerar la organización del espacio como reflejo de una sociedad a partir de sus vínculos con su medio: coerciones, desafíos, riesgos, impactos, etc. Así se han ido acuñando expresiones como paisaje urbano ante una nueva realidad omnipresente, la ciudad, paisaje rurall agrario, opuesto al anterior y precisamente cuando se convierte en una reliquia, paisaje recreativo, generado por «la cultura del ocio» y recogiendo el sentido estético tradicional, arquitectura del paisaje, referida a la recreación del medio para el «consumo» (parques, etc.), paisaje simbólico, paisajes sagrados y un largo etcétera constantemente acrecentado. Sin embargo, entre ellas, nos interesa especialmente la consagración de una, el paisaje cultural, basado en una, como veremos discutible, oposición entre lo natural y lo cultural, y dentro del que se incluirían tanto el paisaje histórico como el paisaje arqueológico ${ }^{6}$.

\footnotetext{
${ }^{6}$ The Cultural Landscape, 1988.
} 
II. El PAISAJE DE LA hiSTORIA Y DE LA ARQUeOlogía: LA GÉNESIS DE UN TEMA DE ESTUdio (FIG. 1)

- Tendríamos que remontarnos al siglo XVIII para encontrar, por vez primera, un considerable volumen de documentación consagrado al estudio del espacio, en forma de descripciones destinadas a la planificación y control por parte de los estados — censos, catastros, inventarios-dentro de lo que se llamó Estadística. Pero el paisaje sigue siendo terreno de los artistas, y como tal, recoge todos los elementos que imprimen ese carácter idílico, entre ellos las ruinas.

Esta preocupación política y económica genera la necesidad de sistematizar las distintas unidades constitutivas del espacio y los factores que se integran en él, proceso ligado a unas notable mejoras técnicas, en especial en el ámbito de la cartografía.

- A lo largo del siglo XIX el paisaje va rompiendo su tradicional vínculo con el mundo de la expresión artística al entrar a formar parte del vocabulario de los geólogos primero, y de la Geografía física después: el paisaje se identifica con el aspecto topográfico que traduce una serie de procesos. De aquí surge la asociación del término al medio físico - lejos aún de implicar postura deterministas. Sin embargo, no se emprende una definición del vocablo que, en rigor, sigue perteneciendo casi exclusivamente al arte.

Desde los años centrales del siglo se empieza a detectar el impacto del evolucionismo planteado en la obra de Darwin: se suscitan una serie de cuestiones que tendrán una dilatada repercusión: las nociones de adaptación al medio, lucha por la supervivencia o selección natural generan una nueva visión del medio en el que se mueve el hombre y a cuyos condicionantes responde su trayectoria física y cultural?

Así, a lo largo de esta centuria surgen iniciativas e intuiciones que van gestando el debate que, a caballo entre los dos siglos, se generará en torno al paisaje: Michelet, al afirmar por vez primera la necesidad de hacer una lectura histórica del paisaje es un auténtico pionero; el avance de la "Geografía clásica» de manos de Humboldt y Ritter, la entrada de la Historia y la Geografía en ámbitos académicos, el citado darwinismo... Se inician diversas aproximaciones al paisaje desde diferentes ciencias y posturas, sin llegar nunca a fijar una definición para el uso científico del término: este será el origen de la ambigüedad y polivalencia del vocablo. Incluso en las obras de los dos grandes geógrafos franceses que en los últimos años del siglo personalizaron el positivismo —agudizado en el determinismo geográfico-y el posibilismo, Raetzel y Vidal de la Blache, el término es usado de una forma confusa.

Sin embargo, la aportación de Vidal de la Blache ${ }^{8}$ merece una mención algo más detallada. Origen del enfoque regional, de enorme éxito en las humanidades en Francia y en los ámbitos académicos de gran parte de Europa, incluida España, Vidal de la Blache considera que todos los rasgos que caracterizan y singularizan una región —objeto de estudio específico de la Geografía-, es decir, el clima, la vegetación, el relieve y la actividad humana en todas sus vertientes, se plasman en un paisaje específico, resultado de la integración de todos estos elementos a lo largo del tiempo. Sin embargo el paisaje es considerado como algo atemporal: en su estudio es un dato dado.

7 Renfrew-Bahn, 1991, 24

8 Vidal de la Blache, 1905; idem 1922 (recopilación de sus trabajos fundamentales por E. de Martonne). 
En realidad en la obra de Vidal no se acomete el análisis del concepto - aunque si se hace con otros como el de región, modos de vida, etc.—, sin embargo entre los geógrafos que dieron forma a lo largo de los sesenta años siguientes al enfoque regional surgieron importantes apreciaciones y precisiones, en especial en la obra de Fochler-Hauke (Fochler-Hauke, 1959) que propone una clara diferenciación entre región, definida por límites administrativos y paisaje, como un territorio científicamente definido. Desde esta perspectiva plantea FochlerHauke cinco vías posibles de acercamiento científico al paisaje: morfológica, ecológica, cronológica, regional y clasificación de paisajes.

- Así pues, hasta este momento, tanto el empleo del término como las matizaciones procedían de los geógrafos y, en especial, del regionalismo. En los primeros años del siglo XX una serie de geógrafos franceses advierten los vacíos e inexactitudes del enfoque predominante (Gallois y sus trabajos sobre toponimia, Sion, Febvre, etc.), pero es sobre todo en la década de los treinta cuando surgen, casi simultáneamente, una serie de aportaciones clave, de manos, por vez primera, de historiadores: se trata de M. Bloch y R. Dion desde los estudios del mundo medieval, y de A. Déléage desde la Antigüedad ${ }^{9}$. Sus aportaciones son indisociables de las propuestas que se estaban gestando en torno a los Annales y su interés por la Historia social y económica.

Recogieron las sugerencias contenidas en la obra de Vidal sobre la necesidad de tener en cuenta las relaciones entre el hombre y el medio, que se completaron con ideas procedentes de la Sociología. Se propone entonces, explícitamente, una visión histórica del paisaje, identificado, casi exclusivamente, con el paisaje rural agrario. Se propone un trabajo en sentido diacrónico desde una colaboración interdisciplinar, aunque, en la práctica, la sugerencia quedó bloqueada en dos direcciones: por una parte por la consagración de tópicos que tenían mucho que ver con la visión tradicional idílica del paisaje (el bosque primitivo, las roturaciones medievales, etc.), y, por otra, porque se consideraba el final del primer milenio como el año cero en la historia de los paisajes. Se generó un análisis lineal y con mucho de literario.

- Estos trabajos marcarían la tónica general del estudio de los paisajes desde un punto de vista histórico hasta la Segunda Guerra Mundial, en especial en Francia, cuna de estos autores, se cayó en una monotonía y falta de creatividad, con enorme arraigo del regionalismo que alcanzó hasta la década de los setenta.

Sin embargo, en torno a los años de la Segunda Guerra Mundial, se estaban poniendo en marcha en otros paises europeos iniciativas y proyectos más abiertos y renovadores, de nuevo casi exclusivamente entre medievalistas. Así, la trayectoria de la rica, y muy desconocida entre nosotros, investigación de los países nórdicos culminó con la puesta en marcha del Nordic Deserted Farm Proyect, que desde una perspectiva histórica y ecológica emprendió en análisis del poblamiento rural escandinavo e islandés entre los siglos XIV y XVII, analizando su huella en la organización territorial y deteniéndose en la plasmación en el paisaje de los cambios que se produjeron en la Baja Edad Media. Jankuhn en Alemania se sitúa a la cabeza de la Siedlungsarchäologie, y en los Países Bajos se presentan los resultados de los primeros estudios sobre divisiones agrarias antiguas, los denominados «celtic-fields» (Van Giffen y más tarde Brongers). La aplicación de técnicas de cartografía, fotografía aérea, análisis palinológicos, carpológicos, antracológicos y de fauna y reconocimientos de terreno coordinados hicieron posible avances notables en estos años.

\footnotetext{
9 Bloch, 1952-56; idem, 1961-64; Dion, 1934; Déléage, 1934; Febvre, 1922.
} 
Más influencia, por su mayor difusión, lograron los trabajos emprendidos en Gran Bretaña. Por una parte, contaba con una arraigada tradición de historia medieval nacional, y, por otra, con una experiencia en el trabajo con fotografía áerea desde los pioneros vuelos de Crawford en los años veinte - los primeros realizados en zonas no desérticas sobre un suelo constante y densamente ocupado-. Por otro lado, las investigaciones sobre divisiones agrarias antiguas se remontaban a los años veinte. A este bagaje se une el desarrollo de los primeros trabajos de campo extensivos (excavaciones de la Isla de Man).

Los estudios de estos medievalistas no consiguieron, quizás ni pretendieron, romper con la negligencia tradicional hacia un paisaje anterior al medieval: en sus trabajos, se pretendía limitar espacial y temporalmente un establecimiento rural, estudiar su morfología y, básicamente, su parcelario. Sin embargo, su aportación fundamental fue la puesta a punto, en la práctica, de técnicas y documentos de trabajo y de una colaboración interdisciplinar.

- Dentro del ámbito británico, desde finales de los cincuenta y durante la década de los sesenta, estaban tomando forma y aplicándose las técnicas de lo que se denominaría Field Archaeology, que pretendía analizar las huellas dejadas por el hombre en el territorio mediante todos los medios de documentación posibles y técnicas al alcance (Bowen, Cunliffe, Hoskins, Aston...). Esta tradición se plasmó desde entonces en un marcado interés por la historia de los paisajes antiguos, su morfología, y la posibilidad de detectarlos en los paisajes actuales. Pronto se generó un interés por relacionar la información que proporcionaba la fotografía aérea con una difusa landscapes archaeology. Todo ello fue recogido y asimilado en la excepcional obra de Bradford de 1957 Ancient Landscapes, dentro de lo que ya quedó consagrado como Landscape Archaeology. El paisaje empieza a ser considerado como un «palipmsesto», expresión usada por Aston y Rowley en 1974 y difundida por Chevallier a partir de 1976.

A este panorama, brevemente esbozado, hay que añadir, por un lado, el acicate que supuso en aquellos años la generalización de la elaboración de inventarios y cartas arqueológicas, que, en principio, obligaban a considerar el hallazgo arqueológico en su marco espacial y en su relación con los demás hallazgos. En segundo lugar, las reformas institucionales en Ministerios de Cultura y Educación y la aparición de organismos consagrados a investigación y gestión de medio ambiente se hacen eco de una nueva consideración del patrimonio y permiten replanteamientos.

Simultáneamente, surgía la primera respuesta organizada y con fuerza al posibilismo vidaliano aún vigente: nace la denominada Nueva Geografía (Schaefer, 1953), apoyándose en el positivismo renovado nacido de la Escuela de Viena. La Nueva Geografía supondrá la consagración del espacio y su organización como tema específico de estudio de la Geografía. Los nuevos geógrafos cambiaron la forma tradicional de entender y representar el espacio y las relaciones que en él se producen (noción de espacio relativo, aplicación de modelos, análisis locacional, técnicas de cuantificación, etc.), y con todo ello, surgen reflexiones teóricas y metodológicas y alternativas para la planificación y gestión del espacio.

- Hacia la mitad del siglo se difunde en el ámbito anglosajón lo que se ha denominado el enfoque ecológico, gracias a la labor del antropólogo norteamericano J. Steward y su equipo, en especial G. Willey. El centro de sus trabajos lo constituye el interés por el cambio cultural, que les llevó a plantear el hecho de que las culturas no sólo interactúan con otras culturas, sino también con el medio: así, el estudio de las formas de adaptación que pueden provocar un cambio cultural genera el nacimiento de la ecología cultural. 


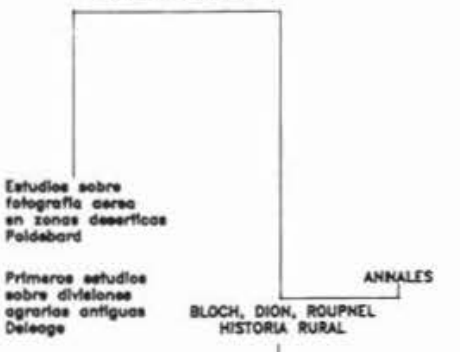

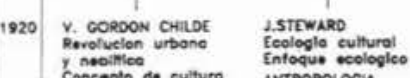

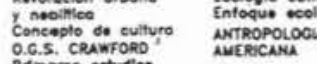

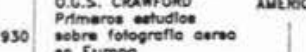

1940

1950

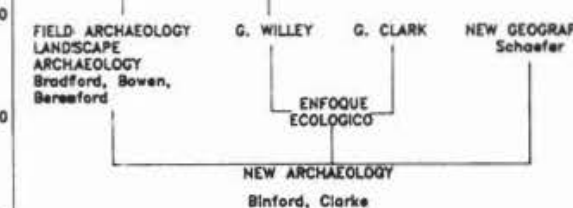
aintord, Clarke

1970

PALERCONOMY

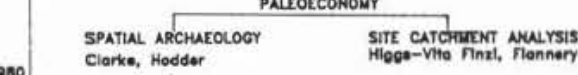

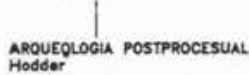

1990 L ENVRONUENTAL ARCHACOLOCY

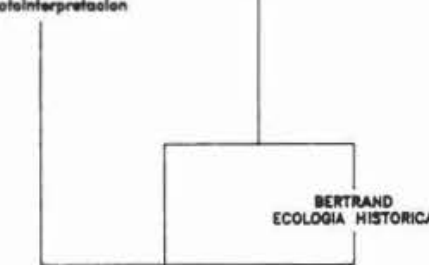
CHEVALEE, AOACHE, OUY 1

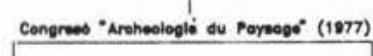

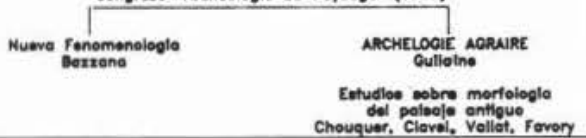

2

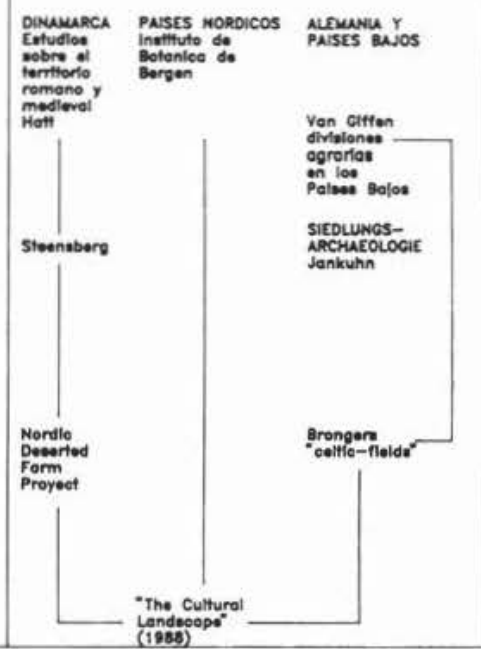

Lendecoop

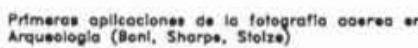

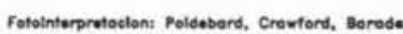

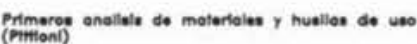

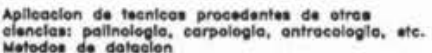

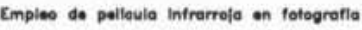

1085- "Seleneses in Arenosooiogr'

$\leftarrow$

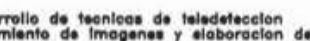

oertogreflic

\section{ARQUEOLOGIA DEL PAISAJE}

Figura 1.-La aportación de las tendencias fundamentales de la Arqueología del siglo $\mathrm{xx}$ a la formación de la Arqueología del paisaje.

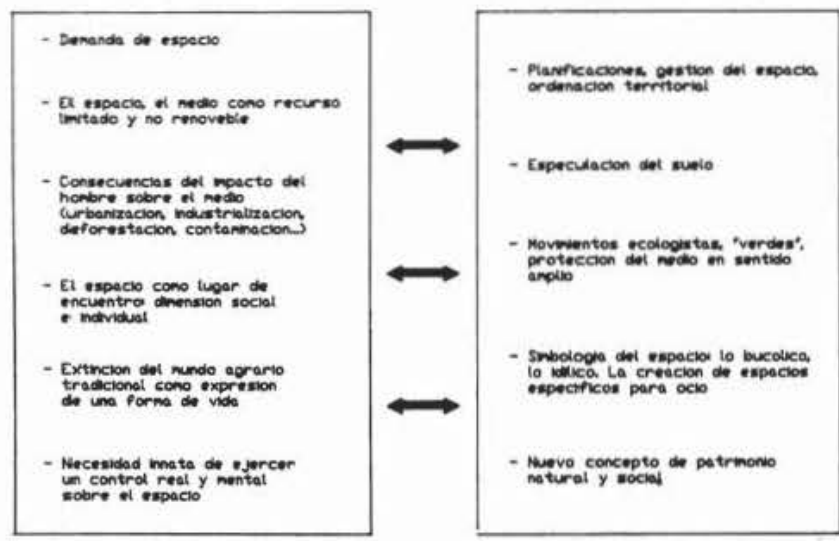

(c) Consejo Superior de Investigaciones Científicas Licencia Creative Commons Attribution (CC-by) España 3.0
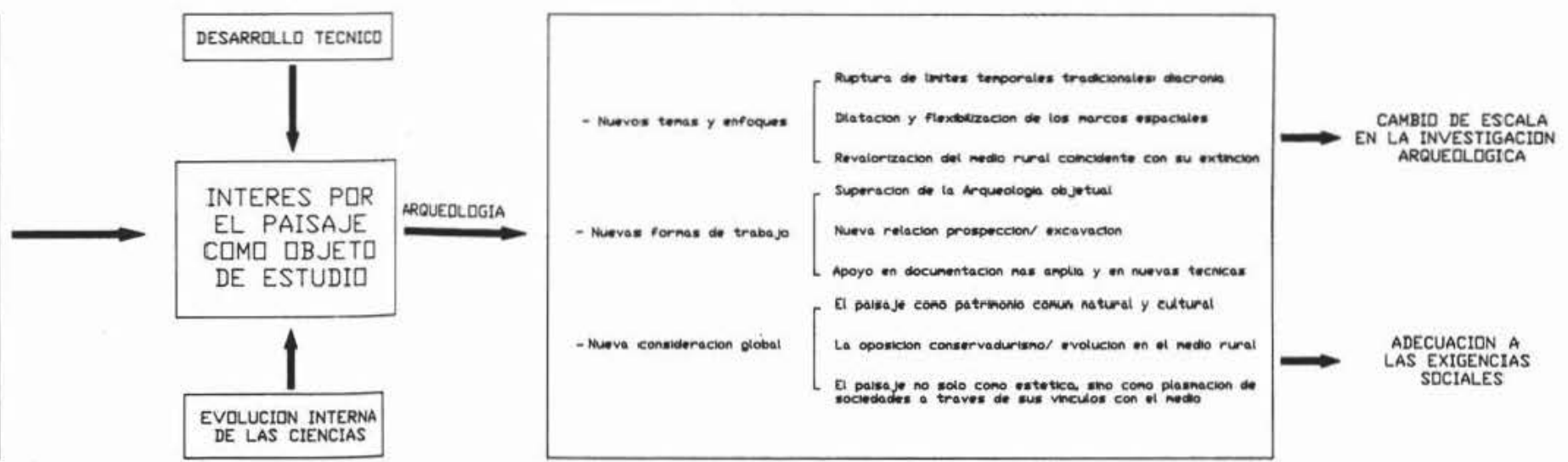

http://aespa revistas csic es/index php/aespa 
Si en el ámbito americano esta aproximación nace desde el campo de la Antropología, en el británico surge de la arraigada field archaeology, en especial de la iniciativa de G. Clark. A lo largo de su trabajo constató un «bloqueo» de la tradicional arqueología basada en el estudio de objetos que suministran una información limitada y propuso el estudio de las relaciones (adaptaciones) del hombre y su medio como fuente de conocimiento de las sociedades antiguas, a partir de una labor necesariamente interdisciplinar (Clark, 1952).

El enfoque ecológico se ha incorporado en las últimas décadas tanto al trabajo de campo en Arqueología como a diversas posturas y tendencias, haciendo de la reconstrucción medioambiental y de las dietas de las sociedades antiguas temas axiales en la investigación. Sus pretensiones se han visto favorecidas por el importante desarrollo de técnicas desde la Segunda Guerra Mundial, en especial de los sistemas de datación y los análisis de restos vegetales y de fauna.

- A finales de la década de los sesenta, las técnicas de la Field Archaeology y las propuestas de la Nueva Geografía sentaron las bases del nacimiento en Gran Bretaña de lo que pronto se denominaría Nueva Arqueología (Clarke, 1968), mientras que, al otro lado del Atlántico, la Arqueología norteamericana, estrechamente ligada a los avances de la Antropología lanzaba propuestas originales en el mismo sentido (Binford, 1968). Ya las primeras iniciativas nacidas dentro del enfoque ecológico, o trabajos como los de Taylor, a finales de los cuarenta, se hicieron eco de un descontento entre una parte de los arqueólogos que partía de la necesidad de explicar los hechos arqueológicos (explanation) sin recurrir necesariamente fenómenos externos a las sociedades estudiadas (del tipo de invasiones o migraciones), y de hacer explícito el razonamiento seguido.

Esta Nueva Arqueología anglosajona, que ha marcado tan profundamente la Arqueología de nuestros días, aunque no emplea en su discurso el término paisaje más que en un sentido coloquial, propone una nueva forma de acercarse al entorno, basada en un funcionalismo ecológico. Se parte de una definición del término territorio, entendido como un conjunto de recursos que ha de estar en equilibrio con la comunidad; la cultura se entiende como una adaptación extrasomática al medio: la ruptura del equilibrio entre los recursos y la comunidad exige una nueva adaptación. Así, en el funcionalismo ecológico quedan subrayados tres aspectos fundamentales:

- las relaciones hombre-medio en términos ecológicos,

- el medio como recurso

- el territorio en su relación estricta con la comunidad

A partir de los planteamientos propuestos por los nuevos arqueólogos, se habían abierto nuevas vías de análisis y nuevos intereses: entre ellos el despertado por el estudio del espacio y del territorio que dio lugar a la Arqueología Espacial y al Site Catchment Analysis (SCA), estudios tanto sobre la distribución de asentamientos como sobre la relación entre ellos y los recursos.

Se empiezan a desarrollar estudios paleoambientales dentro del marco del enfoque ecológico en Gran Bretaña, con escasas repercusiones en el resto de Europa, donde la tradición geográfica francesa, apoyada aún en el regionalismo, se resistía a las técnicas de cuantificación y de aplicación de modelos. Hasta finales de los setenta no entra ni en Francia ni en España la Geografía cuantitativa y prácticamente habrá que esperar una década más para que los arquéólogos se interesen por estas técnicas. 
En los años setenta el nivel y desarrollo alcanzado por los estudios espaciales y territoriales conseguía que el yacimiento arqueológico no fuese considerado fuera de contexto, aunque nunca se habla en sentido estricto de paisaje. Al margen de los aspectos concretos, la Nueva Arqueología provocó un cambio en la visión global de los arqueólogos: por una parte el «principio de autoridad» dejaba de tener valor frente a la necesidad de razonar y explicitar ese razonamiento; por otra parte se descubre la riqueza de una información arqueológica — hasta entonces ignorada - correcta y exhaustivamente manipulada. A partir de ese momento se hizo necesario un replanteamiento de los trabajos de campo y de la escala a la que se realizaba la investigación.

- Simultáneamente, a finales de la década de los sesenta, las tesis ecologistas tienen una fuerte incidencia en la geografía francesa, enlazando con la ya tradicional historia rural desarrollada a partir de los años treinta. En especial tenemos que referirnos a la obra de Bertrand y al nacimiento de lo que él bautizó como ecología histórica (Bertrand, 1975 y 1978).

Bertand parte de una evaluación crítica a las propuestas regionalistas que habían marcado la Geografía a lo largo de sesenta años y que en los estudios históricos habían supuesto la necesidad de dar un marco geográfico a la actividad del hombre, pero que nunca habían profundizado en la relación del hombre con su entorno.

Bertrand abre, conforme van surgiendo los problemas en su investigación, una reflexión sobre el uso y sentido de los diversos términos y su adecuación al objeto de estudio, en especial le preocupa el uso del término paisaje: su ambigüedad, a la que ya nos hemos referido, le lleva a proponer «renunciar a este vocablo en el plano científico, manteniendo su uso en un sentido trivial, y buscar auténticos conceptos, quizás menos ricos por su contenido pero más claros, y, por lo tanto, más operativos» (Bertand, 1978, 133). Al plantear esta necesidad de sustituir el término revisa las alternativas posibles: nicho ecológico, medio geográfico, etc. Finalmente, opta por el de geosistema, entendido como una estructura espacial con un funcionamiento biogeográfico autónomo en que se interrelacionan lo abiótico, lo biológico y lo antrópico.

La arqueología del paisaje tiene que plantearse en el marco de la ecología histórica si se quiere evitar que no pase de ser «una especie de neogeografía agraria formalista y geométrica» (Bertrand, 1978, 132); esta ecología histórica se basa en la dialéctica entre la sociedad y la naturaleza: modo y sistemas de producción no son sino la forma de manifestarse las relaciones ecológicas entre una sociedad y su entorno. Desde este punto de partida, define Bertrand un determinismo ecológico relativo: las sociedades y los paisajes que generan tienen largas etapas de bloqueo en las que el medio es determinante, pero estas fases son rotas por la aparición de hitos agro-técnicos que causan una evolución, una superación de la situación previa, hasta caer en un nuevo bloqueo. En este marco se entiende la aparición de la agricultura como una irrupción en el ecosistema incial que causa la aparición de un nuevo ecosistema con su propio equilibrio: el agrosistema inicial (término que reemplaza el tradicional de espacio rural), seguido por sucesivos agrosistemas. Poner a punto el método ecológico regresivo en historia y arqueología exige una formación ecológica de la que carecen la mayor parte de los investigadores.

En 1977 tuvo lugar en París un congreso bajo el título de Archéologie du Paysage, por iniciativa de R. Chevallier que propuso el título de la reunión. Cuando se bautizó así el encuentro no se hizo sino recoger una ya seria trayectoria desarrollada en la Europa occidental (básicamente Francia e Italia).

$\mathrm{El}$ propio $\mathrm{R}$. Chevallier, un año antes expuso en un breve trabajo algunos de los rasgos y 
problemas fundamentales del nuevo tema bajo el sugestivo título de «Le paysage palimpseste de l'Historie. Pour une archéologie du paysage» (Chevallier, 1976): su gestación, problemas de definición, la consideración del «paisaje humanizado.. expresión objetiva de las civilizaciones», las formas y técnicas de trabajo que permiten superar una visión estrictamente descriptiva y descubrir la dimensión temporal en la espacial, así como la posibilidad de fijar una «tipología de los paisajes fósiles».

En el congreso de 1977 se abordaron tanto el estudio de las fuentes para la Arqueología del paisaje como las técnicas de trabajo, en especial la fotografía aérea y la cartografía, y se presentaron trabajos ya concluidos o en proceso de realización desde la Prehistoria a nuestros días y tanto sobre el mundo rural como sobre el urbano. Se cerró con sesiones dedicadas a cuestiones legales, de conservación y protección de patrimonio y de su planificación más allá del tradicional marco objetual. De esta forma el congreso se convirtió rápidamente en un punto de referencia necesario, al proporcionar una presentación conjunta de trabajos hasta entonces dispersos, abrió debates y planteó perspectivas.

- Sin embargo, sería erróneo presentar un panorama articulado en dos polos: el anglosajón de la Nueva Arqueología y el francés de la ecología histórica y de la arqueología del paisaje - dos trayectorias que, hay que anotar, en la mayoría de los casos se ignoran mutuamente. Simultáneamente están surgiendo propuestas nuevas y críticas a las tendencias imperantes dentro de las ciencias sociales, que van a aportar nuevas perspectivas en la consideración del paisaje como objeto de estudio. Influirá de forma notable, y ya insoslayable en la actual visión, el hehaviorismo o conductismo y la geografía de la percepción y del comportamiento de él derivadas, introduciendo aspectos como la importancia del aprendizaje en la fijación de las relaciones entre el hombre y el medio, la capacidad de simbolización y la creación de imágenes y mapas mentales del espacio (Gould-White, 1974; Lynch, 1960).

También a lo largo de los setenta tomaron forma las propuestas fenomenológicas y existenciales dentro de las ciencias sociales, dando lugar a lo que se ha denominado fenomenología existencial, caracterizada, a grandes rasgos, por una reivindicación de lo individual, lo subjetivo y lo singular. Esta postura generó una nueva concepción del espacio, de forma que la relación que el hombre establece con él sólo puede entenderse en términos subjetivos: surgen conceptos como mundo vivido, experiencias preconceptuales del espacio, topofilia/ topofobia/ toponegligencia (Yi Fu Tuan, 1974), etc.

- Resulta innecesario aquí incidir en las evidentes repercusiones que la Nueva Arqueología ha tenido y tiene sobre la investigación arqueológica actual; pese a la resistencia y reticencias suscitadas, los planteamientos gestados entre los nuevos arqueólogos revitalizaron el panorama científico y abrieron nuevas perspectivas cuando algunas vías parecían irremediablemente bloqueadas (Clarke, 1973).

Una de sus aportaciones cruciales la constitye la necesidad de tener presente la importancia del medio y su equilibrio o desequilibrio con las comunidades. El desarrollo de esta idea, que enlaza con la aproximación ecológica, generó una serie de vertientes de trabajo que se han englobado bajo el título de estudios territoriales o espaciales: nos referimos a lo que dentro de la Paleoeconomy se denominó Arqueología Espacial, Site Catchment Analysis (SCA) y Site Explotation Territory (SET).

Las relaciones entre el ecosistema y el sistema sociocultural funcionan en los dos sentidos y generan tanto una reacción interna en las sociedades como alteraciones en el medio: ambas 
tensiones confluyen para dar lugar a un cambio cultural. Conforme a estas propuestas de los nuevos arqueólogos se generaron estudios sobre la distribución del hábitat antiguo en el espacio, las relaciones que se establecen entre ellos y con los recursos. El desarrollo de estos proyectos es incomprensible sin la difusión de nuevas técnicas y herramientas de trabajo procedentes de otras ciencias, entre las que tenemos que destacar los avances en estudio de flora y fauna (análisis de restos óseos, carpología y palinología) y el análisis locacional de la Nueva Geografía británica (Haggett, 1965).

Tanto la Arqueología espacial con el SCA se gestaron en la Universida de Cambridge hacia los años centrales de la década de los setenta. El SCA fue enunciado por Higgs-Vita Finzi (Vita Finza-Higgs, 1970) mientras K. Flannery (Flannery-Coe, 1969) realizaba en Estados Unidos un proyecto en la misma dirección. En el SCA se considera el yacimiento como el punto central en las relaciones hombre-medio: la mejor posición es la que permite un más fácil acceso a los recursos en sus diferentes niveles (territorios de explotación, territorios anuales, territorios de captación). El análisis se basa en una relación directa poblamiento-medio, entendido éste como conjunto de recursos.

En los mismo años D. Clarke, I. Hodder y C. Orton, entre otros plantean las bases de la Arqueología Espacial, partiendo del estudio de la consideración exacta de los «artefactos» en el yacimiento y de los yacimientos en el espacio. Desde esta nueva perspectiva surge de los datos arqueológicos una información nueva cuantitativa y cualitativamente tras someter los datos a tests estadísticos que generan modelos de ocupación del espacio, tal y como lo había hecho Haggett en su análisis locacional (Clarke, 1977; Hodder-Orton, 1976).

Pese a las resistencia y desconfianzas, en especial en Francia y en la Europa de tradición académica gala, tanto la difusión del SCA como de la Arqueología espacial consiguieron, a nivel general, romper el estrecho marco que imponía la consideración del yacimiento como objeto de estudio exclusivo del arqueólogo. El desarrollo de nuevos planteamientos teóricos, metodológicos y la aplicación de nuevas técnicas de trabajo era ya un hecho irreversible. Hoy, cualquier consideración del entorno, del paisaje, pasa por un reconocimiento de las perspectivas y formas de trabajo propuestas desde Cambridge.

Sin embargo, quedaron al mismo tiempo abiertas las cuatro grandes zonas de riesgo de la arqueología contemporánea:

- la consideración de la dimensión espacial y de los estudios que permiten valorar el medio en su relación con el hombre como meramente ornamentales, reducidos en muchas ocasiones a apéndices de memorias de excavación que nada tienen que ver con el texto al que se adosan,

- la identificación de estudios espaciales con trabajos locales de estrechas miras,

- la aplicación de modelos y/o tests estadísticos de forma indiscriminada, automática, sin una hipótesis de trabajo previa y sin una interpretación de los resultados.

- la existencia de ámbitos de la vida de las comunidades que no quedaban explicados: religión, simbolizaciones, etc.

El paisaje como objeto de estudio en la Arqueología actual: herencias, críticas $e$ indefiniciones

- En los últimos años las diversas alternativas que imprimieron un giro radical en la ar- 
queología de los sesenta han sido sometidas a crítica desde múltiples ángulos y muchos han sido los trabajos que se han ido alejando, matizando u oponiendo a las primitivas propuestas.

A ello ha contribuido el impacto general causado por diversas iniciativas y movimientos sociales, políticos o dentro el mundo científico: entre ellos, las tesis ecologistas han logrado en los últimos treinta años una enorme incidencia en los más diversos ámbitos, que en muchos casos ha corrido paralela a una dispersión y trivialización. Sin embargo, es imposible prescindir de su peso: como hemos mencionado, en Arqueología, tanto en la ecología histórica como en la Nueva Arqueología la perspectiva ecológica ha sido crucial. Junto al ecologismo, dos actitudes han marcado de forma notable la evolución del pensamiento en los últimos años: lo que se ha denominado humanismo, agrupando posturas idealistas y existencialistas, que subraya el nexo afectivo fundamental que marca la relación del hombre con su entorno y ha llevado a una reivindicación del espacio subjetivo, como plasmación de mentalidades, sentimientos y simbolizaciones, y los movimientos denominados radicales dentro de las ciencias sociales que exigen la integración de la ciencia en la sociedad y un compromiso con ella.

No vamos aquí a revisar sistemáticamente las críticas y alternativas propuestas ni a hacer un esquema de las direcciones de las nuevas tendencias y sus motivos, sólo a precisar qué han aportado o están aportando al estudio del paisaje en nuestra ciencia la nueva fenomenología, los arqueólogos postmodernos o postprocesualistas y algunos paises con trayectorias originales.

No podemos dejar de hacer una breve mención a la importancia que el avance de las técnicas tiene en el desarrollo de la Arqueología del paisaje a partir de la Segunda Guerra Mundial: desde los más diversos ámbitos se incorporan formas de análisis y se les da un desarrollo específico, adaptado a las cuestiones que se han de resolver: sin el impulso de la fotointerpretación y teledetección, cartografía, prospección geofísica, palinología, carpología, antracología, análisis de restos óseos, de sedimentos y un largo etcétera, la Arqueología del paisaje, tal y como se concibe hoy, no sería posible.

\section{El ámbito anglosajón}

- Entre una parte de los arqueólogos británicos, ha surgido una conciencia de la necesidad de reflexionar tanto sobre las propuestas teóricas de la Nueva Arqueología como sobre el sentido de la aplicación de modelos y técnicas de cuantificación: no se trata de una panacea capaz de resolver cualquier problema arqueológico, mediante el tratamiento mecánico de una serie de datos, a veces segmentados y heterogéneos, por el contrario, su uso ha de estar necesariamente justificado y responder al marco y evolución de la investigación que se está desarrollando y a cuestiones ignoradas por los arqueólogos de los sesenta y setenta (Hodder, 1984, 1985,1986 y 1987). Sin embargo, hay que insistir en el hecho de que, mientras en el ámbito anglosajón se gestaban estas críticas y se proponían nuevas alternativas agrupadas bajo el título de Arqueología postprocesual, basada en una lectura simbólica y estructural de los elementos arqueológicos —entre ellos la organización espacial—, en el resto de Europa occidental empezaban a circular las primeras traducciones y se ensayaban las primeras experiencias dentrò de la Arqueología espacial y del SCA. 
Así, I. Hodder, principal exponente de esta revisión, incorporando las ideas del neoestructuralismo y neo-marxismo, propone una ruptura con el materialismo y positivismo de la arqueología procesual, que permita superar las tradicionales oposiciones materialismo/idealismo y objetividad/subjetividad (con todas las oposiciones que a su vez ha generado) y realizar un análisis contextualizado de los datos arqueológicos que permita poner al descubierto la relación simbólica, mental, entre las gentes y los modelos espaciales que generaron.

- Recientemente, todas las formas de análisis arqueológico que permiten la reconstrucción de los medios en el que se desarrollan las sociedades se han agrupado, en el mundo anglosajón, bajo la expresión de Environmental Archaeology. En ella se integran tanto los estudios destinados a conocer el medio en sí a diferentes escalas (climas, red hidrográfica, procesos sedimentarios y geomorfológicos en general, flora y fauna, etc.) como a analizar el medio como recurso y las alteraciones provocadas por la presencia del hombre en él: acondicionamiento para hábitat y explotación del entorno - SCA y SET-.

Las iniciativas en este marco son muy abundantes, dentro de una aproximación ecológica y herederas tanto de la Nueva Arqueología como de la Paleoeconomy, - y conscientes de las críticas despertadas - como de la experiencia ya desarrollada en diversas técnicas. Resulta representativa la obra de $\mathrm{K}$. W. Butzer, de la Universidad de Chicago donde ocupa la cátedra de Arqueología medioambiental, en especial su Arqueología. Una ecología del hombre, escrita en 1981 y recientemente traducida. Se centra en las formas y objetivos de un análisis del ecosistema del que forma parte una comunidad o un grupo de ellas, abordando tanto los principios del enfoque ecosistémico como las distintas técnicas que permiten su estudio: geoarqueología, arqueometría, y bioarqueología (arqueozología y arqueobotánica). Propone, como conclusión (síntesis) la forma de realizar la integración espacial y temporal de los datos.

La Environmental Archaeology resume el interés reciente por la arqueología ecofactual frente a la tradición artifactual (Renfrew-Bahn, 1991, 195). Parte del presupuesto de que el medio determina el desarrollo de la vida del hombre hasta tiempos muy recientes; sin embargo, a lo largo del tiempo el grado de dependencia ha ido variando al aumentar su capacidad de intervención, y por lo tanto de alteración, en el medio.

\section{El ámbito francés}

La historia rural, como hemos visto, tiene un fuerte arraigo en la investigación francesa, nacida de los trabajos de geógrafos regionales e historiadores del mundo medieval ha generado una literatura tan abundante como dispersa. Dentro de esta trayectoria se inscriben algunas de las tendencias y proyectos más notables de nuestros días, con nuevos planteamientos de partida, avances metodológicos y aplicación de técnicas más complejas y precisas.

- Las aportaciones de la fenomenología existencial, que más arriba mencionamos, sobre las bases sentadas por la ecología histórica propuesta por Bertrand, ha generado, en el ámbito francés, una nueva fenomenología de la que es exponente cercano la obra Prospections aériennes. Les paysages et leur histoire coordinada por A. Bazzana y A. Humbert, desde la Casa de Velázquez, y que parte de una reivindicación de lo visible (en su caso captado a través de fotografías aéreas oblicuas) como punto de partida para un estudio científico (Bazzana-Humbert, 1983, 9-54). 
Parten de la afirmación de que el paisaje no es sino la imagen que de él tenemos, una imagen conformada por apreciacines individuales y sociales: sólo su contemplación directa permite la captación de toda su complejidad. En su consideración del paisaje como objeto de estudio en Historia es clave la noción de movilidad producida por la tensión entre las tendencias conservadoras y la necesidad de cambio. Proponen hablar, para el paisaje, de un orden por fluctuación, que hace que sea irreductible a modelos y resultados de tests estadísticos, que sólo se admiten como referencias marginales.

Bazzana y Humbert consideran que su acercamiento al paisaje es una «aproximación sistémica» en la que las relaciones lineales son sustituidas por «bucles y espirales» entre los diversos sistemas abiertos y vinculados. En resumen, en su planteamiento es clave la subjetivación del paisaje, el espacio micro-regional como objeto de estudio y la fluctuación como ritmo que rige la evolución de ese paisaje.

Sin embargo, pronto se han advertido los puntos débiles de esta postura, y sobre ella se ha articulado una crítica a cuatro aspectos cruciales (Chouquer, 1990):

—el riesgo de caer de nuevo en descriptivismos

-la tentación de pretender una estratificación del paisaje

- la radicalización del concepto de movilidad

$-\mathrm{y}$ el peligro del localismo que bloquee la posibilidad de generar o integrarse en perspectivas más amplias.

- En la década de los ochenta se han dado igualmente a conocer los primeros resultados de un proyecto de investigación puesto en marcha hacia la mitad de la década de los setenta desde la Universidad del Franco Condado (Besançon) bajo el título de Atlas des cadastres antiques y coordinado por M. Clavel-Lévêque. El interés por la morfología de las divisiones agrarias antiguas no era nuevo, pero en los últimos quince años se ha pasado de un interés difuso y aislado a la generación de un tema de investigación con unos objetivos, metodología y técnicas de trabajo sólidos.

Pero, si algo hay que destacar en los trabajos que se realizan dentro del proyecto es su planteamiento de origen no como estudios localizados en tiempo y espacio, sino ligados a una problemática general que provocó la iniciativa del proyecto en sí: el análisis de las relaciones entre los centros de poder y la periferia. La puesta a punto del tratamiento de los clichés aéreos mediante filtraje óptico abría la posibilidad de contar con unos datos seguros como punto de partida del estudio morfológico. Los resultados parciales de los trabajos desarrollados en Francia e Italia se han dado a conocer básicamente en dos Mesas Redondas en 1980 y $1985{ }^{10}$ y en las abundantes publicaciones de M. Clavel-Levêque, F. Favory, J. -P. Vallat y sobre todo, de $G$. Chouquer y su labor desde la APARCH (Association pour le promotion de l'Archéologie des Paysages)".

- Recientemente se ha publicado bajo la dirección de J. Guilaine (Guilaine, 1991) un volumen con el título de Archéologie agraire que cuenta con la colaboración de diversos espe-

\footnotetext{
${ }_{10}$ Cadastres et espace rural, Besançon, mayo 1980; Les cadastres anciens des villes et leur traitement par l'informatique, Roma, 1985.

11. En especial su Cours d'Archéomorphologie, carto-interprétation et photointerprétation, Besançon, 1990.
} 
cialistas procedentes tanto de la Arqueología (primera parte de la obra) como de las Ciencias Naturales, ya que, como indica el subtítulo, la Arqueología agraria se entiende À la croissée des sciences de l'homme et de la nature. Se plantea en ella el estado de una disciplina que arranca en Francia, como ya mencionamos, de la historia rural cuyas bases sentó Vidal de la Blache y que se ha ido enriqueciendo en especial a partir de la década de los sesenta, tanto impulsada por los avances metodológicos y técnicos como por la evolución interna de la Arqueología, el descubrimiento de la ecología, una reivindicación del medio rural y una nueva consideración cuantitativa y cualitativa del patrimonio.

Los trabajos reunidos constituyen una presentación de lo que se ha hecho y se está realizando, tanto como un reconocimiento de sus indefiniciones y su inmadure $\%$ de la necesidad de superar estrechos marcos cronológicos y temáticos. La Arqueología agraria, así planteada, quedaría incluida dentro del más dilatado campo de la Arqueología del paisaje.

Se plantea, en resumen, la reivindicación definitiva de la Arqueología como una «cienciapuente» cuya evolución pasa por una labor interdisciplinar, posición que permite, no sólo un enriquecimiento del arqueólogo, sino también de la visión de las ciencias con las que colabora y que hasta ahora habían prescindido de él.

- La selección de estas tres tendencias de trabajo no implica que el panorama francés esté limitado a ellas: habría que añadir el pionero trabajo desarrollado por los paleolitistas (Lumley), las distintas mesas redondas y congresos en torno al tema de las primeras comunidades campesinas, el desarrollo de las técnicas de teledetección e interpretación de los datos (Chevallier, Guy, Agache), o el desarrollo de una «acción temática programada» del CNRS en el marco del Programme Interdisciplinaire de Recherche sur l'Environnement a partir de 1986 bajo el título L'Histoire de l'Environnement et des phénomenès naturels. No obstante son referencias válidas para entender las perspectivas de mayor entidad.

\section{La aportación de los paises nórdicos: Noruega}

La investigación arqueológica desarrollada en los países del Norte de Europa es escasamente conocida. Sin embargo, ya mencionamos, muy brevemente, las importantes aportaciones que se comenzaron a realizar en los años inmediatamente posteriores a la Segunda Guerra Mundial. La publicación, en inglés, de un congreso organizado en 1986 por el Instituto de Botánica de la Universidad de Bergen en Noruega bajo el título de The Cultural Landscape. Past, Present and Future constituye una buena muestra de la dirección de la investigación apoyada sobre una ya larga serie de proyectos y análisis.

Pese al título del symposium, se plantea desde las primeras páginas la falacia de la expresión paisaje cultural, al menos para el mundo europeo occidental, donde se centran los estudios: sólo tendría sentido por oposición a un paisaje natural virgen y éste, hoy en día, es una ficción. Los diversos estudios se plantean tanto en términos ecológicos, agrupándose bajo la paleoecología, asumida como una ciencia histórica, como sociológicos: las dos vertientes generadoras del paisaje e indisociables en su estudio.

Los trabajos presentados se centran, casi exclusivamente, en los datos elaborados a partir de los abundantes y minuciosos análisis polínicos realizados para el estudio de paisaje de la sociedad preindustrial en el Oeste de Suecia, eje del congreso: a partir de ellos se realizan re- 
construcciones de paisajes y de las formas de vida que los generaron y a que dieron lugar, llegando a la conclusión general de la necesidad de rechazar la idea de una oposición radical entre el paisaje natural (= paisaje no cultivado)/paisaje cultivado y reconocer el impacto creciente, aunque no con un ritmo regular, del hombre sobre el medio. Esta aproximación exige desprenderse de tópicos cronológicos y esquemas preconcebidos sobre cómo se sucedieron las formas de intervenir en el medio: esa ruptura es la que hace que el paisaje del pasado no pueda ser separado del presente ni del futuro.

\section{La tradición italiana}

Desde los primeros años del siglo en Italia se desarrollaron estudios sobre topografía urbana antigua, apoyada desde sus inicios en la fotogrametría y en la fotografía aérea (trabajos de Boni sobre el foro romano, Lugli, etc.). Desde la década de los cincuenta Italia fue centro de trabajo de investigadores de muy diversos origen como Minto, Bradford, Chevallier, Castagnoli, y al interés por las ciudades antiguas se unieron los primeros estudios sobre divisiones agrarias griegas y, sobre todo, el sistema de centuriaciones romanas en el que destaca la labor de Schmiedt y Chevallier. Schmiedt puso en marcha el proyecto del Atlante Aerofotográfico delle sedi umane en Italia, concebido como un atlas de topografía antigua en Itatlia, cuyo tercer volumen acaba de aparecer.

Así, hacia la mitad de la centuria quedaron consagradas las dos líneas fundamentales que aporta la tradición italiana al estudio de los paisajes antiguos: el paisaje urbano y el agrario. Ambas líneas tienen continuación en nuestros días, la primera, en especial gracias a la labor del Instituto de Topografía Antigua de la Universidad de Roma, y a la convocatoria de frecuentes congresos y reuniones sobre el tema; la segunda, en la que tuvo un papel motor esencial la obra de Sereni en los años sesenta, gracias a los fructíferos trabajos tanto de investigadores italianos, en especial las actividades de las universidades de Padua, Siena, Pisa y Pavía, como franceses, como G. Chouquer o F. Favory ${ }^{12}$.

En 1988 tuvo lugar en Pisa un congreso de La Cartografía Archeologica. Problemi e prospettive, en él se abordaron proyectos como la Forma Italiae y diversas cuestiones en el marco de la archeologia territoriale, ligada a la planificación y a la realización de cartas arqueológicas; algunos de los trabajos presentados recogen propuestas del ámbito británico (a través de los trabajos difundidos en la revista de la Escuela Británica en Roma, Papers of the British School at Rome) y orientadas hacia la archeologia del paesaggio, muy reciente en Italia hasta ahora ligada a los estudios clásicos y a un enfoque de la arqueología próximo a la Historia del Arte (Cucini, Guideri, Paolucci, Valenti, 1988, 53-101; Cambi, 1988, 217-227). Así define $S$. Guideri la arqueología del paisaje en la presentación de su trabajo: «L'archeologia del paesaggio sarà quindi, nelle nostre intenzione, quella disciplina che indaga $i$ processi di transformazione dell'insediamento umano nello spazio e nel tempo. Il suo oggetto: non solo l'insediamento umano, ma la complessità delle sue transformazioni. I suoi mezzi: un approccio regionale ed una impostazione interdisciplinare e diacronica». (Guideri, 1988, 79).

12 Buena muestra de la evolución de las investigaciones italianas en el estudio de las divisiones agrarias antiguas es la publicación en Módena, entre 1983 y 1985 de la serie Misurare la terra. 


\section{El panorama español}

Hasta hace pocos años la Geografía española ha permanecido muy arraigada al enfoque regionalista nacido y desarrollado en Francia: de esta visión ha surgido la tradición de abrir los trabajos de Historia o Arqueología con una «introducción geográfica». Así, a las publicaciones sobre Arqueología, se les anteponía un marco geográfico y, en el mejor de los casos, se cerraban con una seire de apéndices en los que se incluían los resultados de análisis o estudios específicos sobre flora, fauna, metales, etc.: ni uno ni otros tenían, de hecho, nada que ver con la exposición del tema. Algunos autores han asimilado rápidamente este tratamiento y la presentación neutra de la información a una «arqueología del paisaje», que no hacía sino recoger los datos ajenos al yacimiento o yacimientos en sí, y han asumido sin ningún problema el título.

Por otra lado, a lo largo de la década de los ochenta, con un considerable retraso, y mezcladas con las críticas que ya se estaban gestando, se fueron difundiendo en el panorama arqueológico español las ideas de la Nueva Arqueología, las propuestas de la Arqueología Espacial, del SCA y del SET. Las reacciones fueron desiguales, y de ellas es buena muestra la serie Arqueología Espacial que desde 1984 recoge los trabajos presentados en sucesivos coloquios organizados por el Colegio Universitario de Teruel: del entusiasmo al escepticismo y con resultados muy heterogéneos. Junto a propuestas originales que adoptaban y adaptaban correctamente técnicas y propuestas anglosajonas surgieron trabajos que cayeron en localismos de estrechas miras o en la aplicación mecánica de técnicas de análisis.

Por lo demás, la arqueología del paisaje en España, entendida en un sentido dilatado, apenas si tiene una presencia testimonial e incipiente, carente de una definición clara, de objetivos y sistematización de la forma de trabajo. Como muestra, en 1988 W. Kurt publicó unas páginas bajo el título de Arqueología y paisaje en las que plantea un estudio del paisaje, por una parte subordinado al proceso de excavación y, por otra, considera "paisaje» y «territorio» como «términos idóneos para denominar el medio extracultural» (Kurt, 1988, 6). La dispersión de los datos, su mera yuxtaposición, la ausencia de un tratamiento interdisciplinar que permita una integración de la información, han hecho, hasta ahora, imposible un planteamiento serio. Quizás mención aparte merezca el trabajo, coordinado desde la Universidad de Santiago, por Felipe Criado sobre el paisaje megalítico, algunos de cuyos resultados abren interesantes perspectivas (Criado et alii, 1986).

No podemos tampoco dejar de mencionar los recientes trabajos sobre divisiones agrarias antiguas que, recogiendo la experiencia y técnicas de trabajo desarrolladas en Francia (en especial el grupo de Besançon) e Italia presentan los primeros resultados para la Península Ibérica: la reciente tesis doctoral presentada por Rosa Plana en la U.A. de Barcelona (Plana, 1990) sobre el Nordeste de la Península ofrece un claro ejemplo del impulso que están tomando estos estudios.

Sin embargo, estos trabajos, aunque empiezan a abrir líneas y formas de investigación, no son sino piezas dispersas que no han llegado a dar forma a una Arqueología del paisaje fundamentada: falta tradición, medios en muchos casos, voluntad de trabajo en equipo - hacia el que tanto recelo existe- y, sobre todo, una seria reflexión sobre lo que estamos haciendo y pretendemos hacer con el volumen de información que, potencialmente, podemos obtener, dentro de una perspectiva amplia y flexible. 


\section{El. paisaje, ¿UNA ARQUEOLOGía IMPOSIBLE?}

\section{Qué estudia la Arqueología del paisaje: objetos y objetivos}

Las diferentes trayectorias, enfoques y perspectivas más recientes que brevemente hemos esbozado han contribuido y están contribuyendo a dar forma a la Arqueología del paisaje que, sin embargo, no siempre se entiende de la misma forma. Efectivamente, por una parte, la expresión arrastra la ambigüedad a la que nos referíamos al hablar del término paisaje y, por otro lado, la diversidad de enfoques y tradiciones que confluyen en ella hacen que, en una gran parte de los casos, su aplicación este vaciada de un contenido específico y sea usada bien con un carácter pretencioso o romántico, para referirse a la descripción del entorno inmediato de un(os) yacimiento(s) en términos de marco en que se desarrolla la actividad del hombre, bien con la aspiración de conseguir una reconstrucción ideal, fotográfica de una zona en un determinado momento histórico, casi siempre ligada al proceso de excavación.

Sin embargo, la herencia de la Nueva Arqueología, de los estudios espaciales y territoriales por ella potenciados, de los enfoques ecológicos en general y la ecología cultural y ecología histórica en concreto, tanto como la nueva concepción del patrimonio histórico y el nacimiento de una demanda social nueva, permiten referirse a una cuestión más compleja que exige precisiones en su definición, fijación de objetivos y formas de trabajo específicas.

La opción de conservar el término paisaje, pese a toda la problemática suscitada, responde, precisamente, a la posibilidad de aprovechar esa globalidad que sugiere: es cierto que en algunas ocasiones puede suponer una pérdida de precisión, sin embargo, esto puede ser fácilmente soslayable mediante el empleo de expresiones más adecuadas para referirse a determinados aspectos: territorio, cuando implique una vinculación directa y reconocida del espacio con una(s) comunidad(es), recurso o conjunto de recursos, medioambiente o medio cuando la referencia sea estrictamente contextual, etc.

Así, en el estudio del paisaje se considera la relación (o la evolución de las relaciones) del hombre con su entorno - en términos ecológicos - que es tanto marco (escenario) de su vida, como recurso, obstáculo, forma de comunicación y plasmación de intereses, relaciones, mentalidades, etc., y, por lo tanto, indisociable de las necesidades y capacidades de la comunidad, de forma que se diluye si desaparece alguno de los elementos, tanto como si se presenta en forma de estudio meramente yuxtapuesto de los mismos. Evidentemente, como plantearemos a continuación, esta forma de afrontar el paisaje va mucho más allá de una mera reconstrucción de una imagen, de una maqueta, e implica proceder por niveles que van desde lo directamente detectable (elementos morfológicos) a la interpretación más compleja de los mismos (simbolización, etc.).

Por otra parte, esta visión parte de la necesidad de superar el estudio objetual que ha marcado y marca en muchos casos aún, la investigación arqueológica, sea ese objeto una pieza, un asentamiento, una construcción singular o una forma de división agraria: esto implica, directamente, romper con la tradicional concepción de una gradación entre la prospección como mera forma de detección de excavaciones potenciales, el sondeo como forma de precisar el interés de un yacimiento y la excavación como culminación del proceso y única forma de obtener información válida.

Una de las cuestiones más complicadas y resbaladizas a la hora de emprender un estudio 
dentro de este marco está en la fijación de los límites de un paisaje: se corre el riesgo de exigirle unas fronteras preestablecidas. Es evidente que hay que trabajar dentro de unos límites espaciales que, en principio pueden fijarse por distintos criterios, pero que siempre han de ser flexibles, discontinuos, como lo son en realidad. Este problema ha de resolverse partiendo de la definición misma que hemos propuesto: los límites no son físicas ni humanos, sino ambos a la vez y oscilan según cambian las relaciones entre ambos polos - puesto que el paisaje es una plasmación de estos vínculos y su evolución-y, por lo tanto, la delimitación de un paisaje sería el último punto de la investigación. La instalación de falsas fronteras, en un sentido u otro, es uno de los errores más frecuentes y que pueden conducir a bloqueos en la investigación y a la fijación de relaciones artificiales, por ello, resulta más adecuado trabajar sobre límites parciales, siendo conscientes de su provisionalidad, susceptibles de dilatarse o contraerse según las exigencias de la investigación.

Pero, ¿qué estudia en concreto la Arqueología del paisaje? La cuestión se podría resolver fácilmente diciendo "el paisaje» o "todo». Retomando los aspectos que han quedado expuestos de forma dispersa en apartados anteriores, podríamos afirmar que en la arqueología del paisaje quedan integradas diversas trayectorias y enfoques de la investigación arqueológica y de otras ciencias (fig. 3): por una parte la tradición de estudios sobre topografía urbana antigua, por otro lado la arqueología del mundo rural, formada por diversas contribuciones, desde los estudios de medievalistas sobre el mundo agrario, basados en documentación literaria, a las más recientes investigaciones sobre divisiones agrarias antiguas, pasando por el estudio de tecnología minera antigua y morfología de las explotaciones; en tercer lugar los estudios destinados a conocer el mundo del comercio y de las comunicaciones en diversas épocas. A estas líneas habría que añadir el más reciente desarrollo de todos los trabajos destinados al estudio de las relaciones espaciales y paleoambientales.

Lo esencial en la gestación de una arqueología del paisaje sobre una base sólida que le otorgue especificidad, es evitar considerar que se trata de una mera yuxtaposición de diversos estudios desde diferentes ángulos de visión: la integración de todos ellos, desde una forma de trabajo nueva y propia es la única vía posible. Se trata, dicho de otra forma, de rechazar el paisaje visto como una serie de trazos o puntos sobre un mapa mudo sin ninguna coherencia (hábitat, divisiones agrarias, explotaciones mineras, etc.) o, a la inversa, como un espacio neutro en el que se van salpicando elementos como si se tratase de una carta arqueológica más o menos compleja.

\section{Las formas y documentos de trabajo:}

\subsection{Las fuentes "externas»: documentación literaria e iconográfica antigua y moderna}

Desde siempre el hombre ha manifestado su interés por representar y describir su entorno desde diversos puntos de vista: planificaciones, administración, fiscalizaciones, comunicaciones, interés estético, docente, explicaciones religiosas, etc.; este es el motivo de que haya llegado hasta nosotros documentación sobre los paisajes antiguos aunque, no hay que olvidarlo, esta información está filtrada según la intención que impulsó la ejecución del documento: es ya una interpretación del espacio.

Resumiendo, podemos indicar que los datos nos han llegado bajo dos formas diferentes: 
en textos y en imágenes. Los textos van desde lo estrictamente literario, que incluye alusiones más o menos dispersas al aspecto u organización del paisaje, a descripciones que mezclan lo geográfico lo etnográfico, lo histórico y lo anecdótico - Herodoto, Estrabón o los libros de viajes - o tratados sobre el tema — como los de los agrónomos latinos, Varrón. Columela o Plinio - o documentos administrativos —como los referidos a repartimentos, repoblaciones, etc., en la Edad Media.

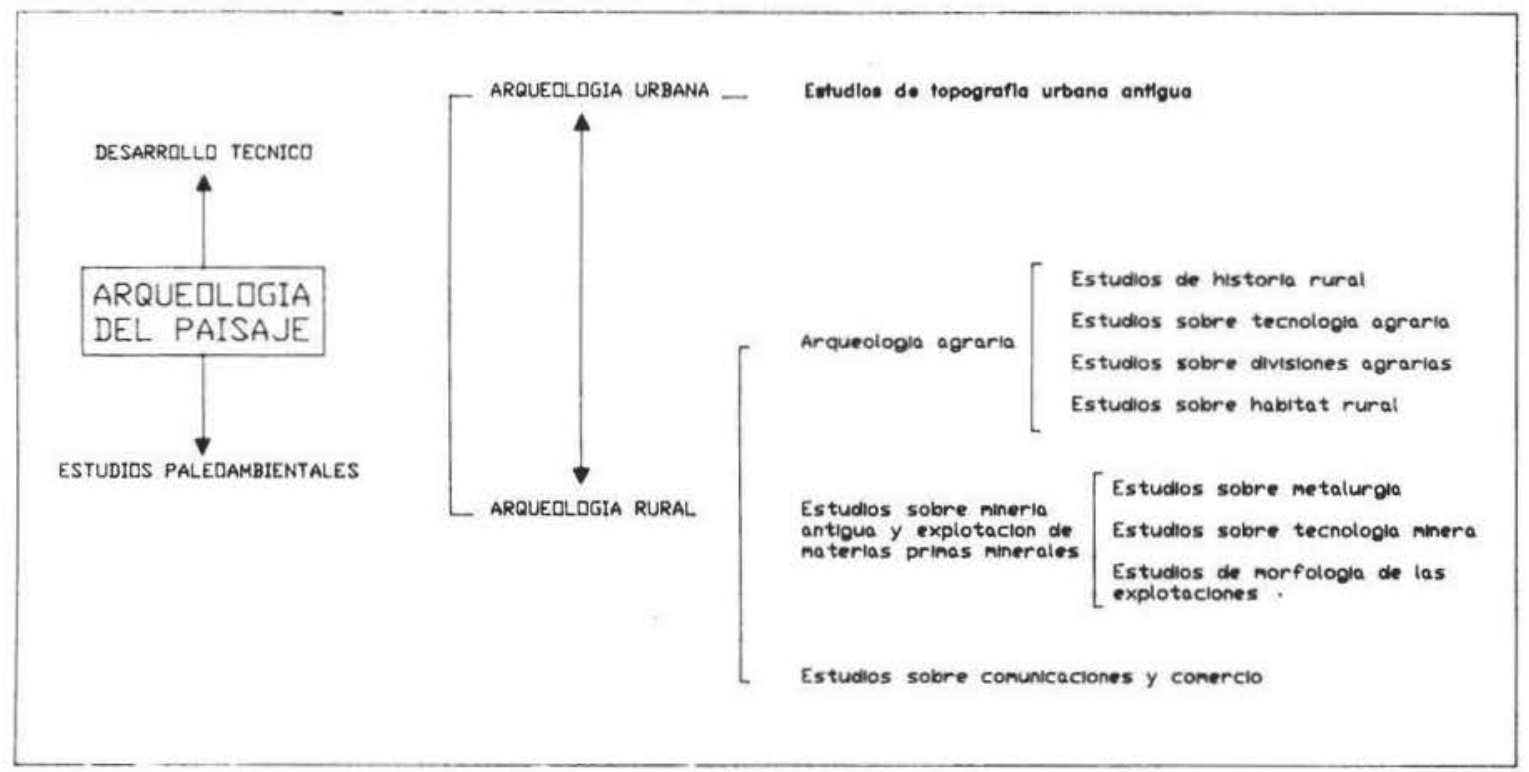

Figura 3.-Campos de estudio que integra la Arqueología del paisaje.

Las fuentes iconográficas, grabados, dibujos, fotografías, etc., pueden suministrar también un importante volumen de información, plasmación de la necesidad del hombre de representar e interpretar el espacio en que se desarrolla su existencia: planos de ciudades, mapas de rutas marítimas o terrestres, representaciones artísticas de espacios de recreo, de trabajo, simbólicos, etc. La lista también aquí sería interminable (fig. 4).

La documentación epigráfica, es, ocasionalmente y en especial para el mundo romano una fuente rica de información para el estudio del paisaje: hitos terminales, miliarios, algunos aspectos de la legislación municipal o documentos excepcionales como el catastro de la colonia romana de Orange son testimonios directos de las formas de la gestión del territorio.

A nivel general y en algunos casos concretos, como el de Orange, estos documentos aportan datos esenciales, sin embargo, cubren una pequeña parte del estudio del paisaje, por un lado debido a su escasez y segmentariedad, por otro dada su marcada intencionalidad.

\subsection{El paisaje como documento}

Junto a toda la documentación que hemos considerado como «fuentes externas», diferentes avances técnicos han hecho posible la lectura de diversos elementos que, conservados en el paisaje actual, contienen información sobre el paisaje del pasado. La detección y análisis de 
tales elementos. pasa necesariamente por tratamientos técnicos de diverso grado de complejidad: no se trata de que el arqueólogo del paisaje sea especialista en todos ellos, pero si ha de conocer sus posibilidades, limitaciones y lo que puede esperar de cada uno. Todo ello quedaria integrado en lo que en el mundo anglosajón se ha bautizado como environmental archaeology. Aunque de una forma artificial, a efectos de la exposición. vamos a dividir esta infor-
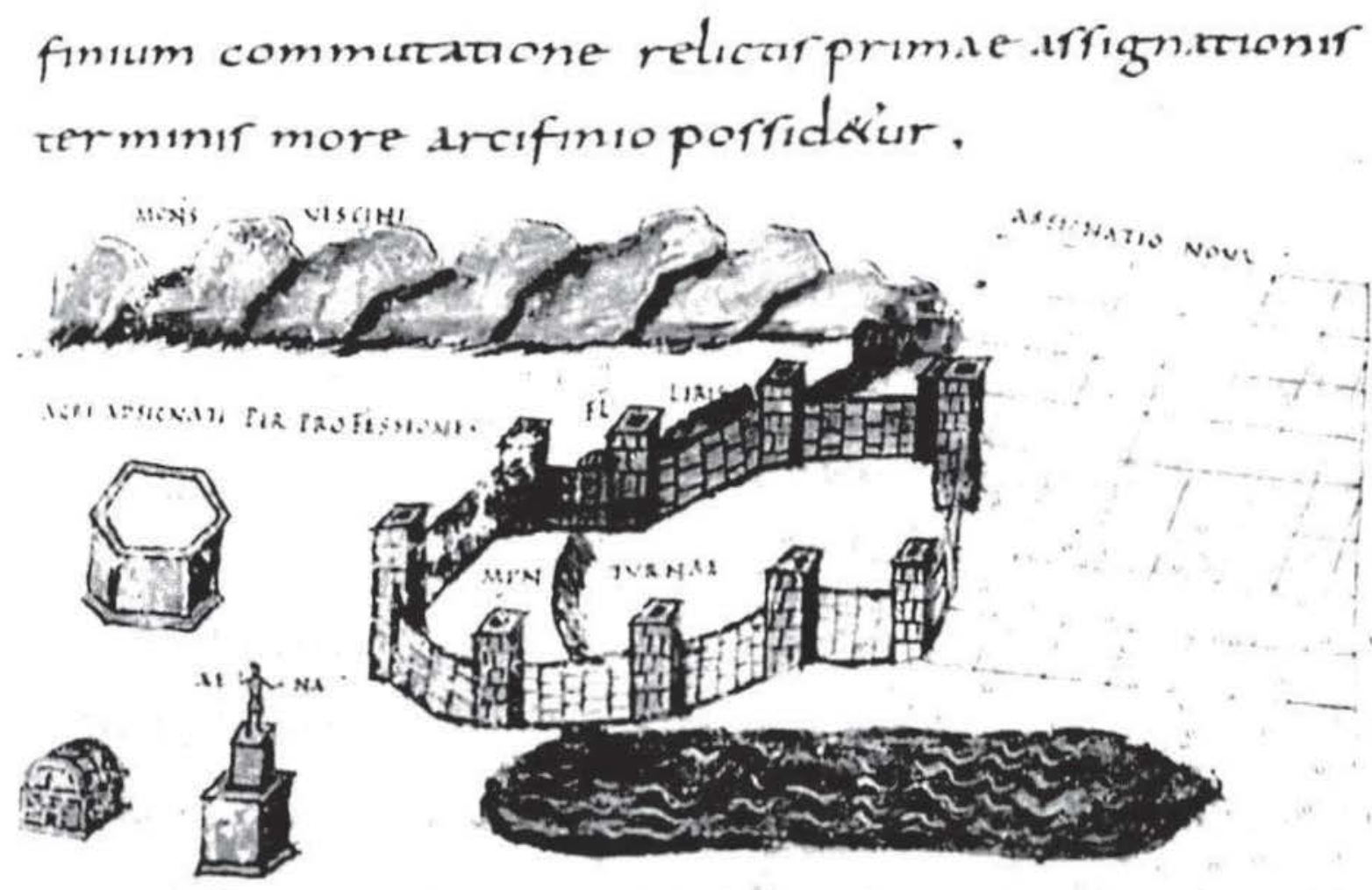

\section{Mular ergo generibur limrum conftrationer in chorae rume quiburdam colonis. $\dot{k} \cdot \dot{m} \cdot \alpha \cdot \dot{0} \cdot \dot{m} \cdot$ non}

Figura 4.-Miniatura procedente del texto de Hyginus Grommaticus.

mación en dos bloques: por una parte la procedente del análisis de restos materiales del pasado, testimonios directos tanto de las características del entorno como del vínculo que lo unía al hombre, preservados, por distintos motivos, hasta hoy, es decir, pólenes, restos de fauna, semillas, maderas y carbones, etc. No vamos a entrar en las posibilidades de cada una de estas vertientes, ya descritas en muchas ocasiones ${ }^{13}$, pero es necesario anotar que su inforamción

${ }_{13}$ Ver, por ejemplo, el reciente resumen de Renfrew y Bahn. 1991, 195-232. Para la aportación de la palinología los resultados reunidos en el congreso sobre The Cultural Landscape, 1988. 
es insustituible y, en general los datos disponibles son aún muy escasos —en especial en nuestro país-y reducidos a los materiales procedentes de excavaciones ya realizadas.

En segundo lugar, nos vamos a referir con más detalle al estudio de lo que podríamos denominar «el paisaje a partir del paisaje», precisando más, al estudio de la morfología de los paisajes antiguos a partir del estudio morfológico de los paisajes actuales, reflejo tanto de las relaciones presentes entre hombre y medio, como de los vínculos que ligaron a ambos en el pasado. Se trata de considerar el paisaje en sí como documento que permite leer en lo espacial la dimensión temporal —asociación reconocida por los geógrafos ya desde finales del XIX-, pero que no implica la realización de una estratigrafía del paisaje, sino la historia de una reutilización continua, cambiando o no de uso.

El trabajo que proponemos consta de tres niveles interdependientes:

- un primer análisis estrictamente morfológico, destinado a la detección de elementos,

- un segundo paso lo constituiría la identificación de los elementos reconocidos,

- y una tercera fase interpretativa.

Aunque esta secuencia parece obvia, es necesario tener presente la distinta naturaleza del trabajo que se desarrolla en cada una de ellas y los riesgos que supone el paso a la siguiente: mientras la primera fase de trabajo, en la que vamos a centrarnos, se basa en la aplicación de una serie de «claves de lectura", la segunda y la tercera dependen de los conocimientos, intenciones y capacidad del investigador y en ellas se corre el peligro de caer en asociaciones directas y correspondencias fáciles que no necesariamente responden a la realidad, del tipo de asimilar determinados elementos morfológicos a funciones, por ejemplo, asociar una morfología agraria con una determinada forma la propiedad es, casi siempre, inseguro.

Partimos de que el paisaje es el resultado tanto de la adaptación del hombre al medio como de la superación de los obstáculos que ofrece y de la alteración de sus condiciones: desde el momento en que el hombre interviene en el entorno, surge una diversificación de espacios en función del uso otorgado a cada uno de ellos, espacios que se van progresivamente racionalizando, delimitando $y$ «diseñando».

\section{El análisis morfológico de los paisajes: instrumentos de trabajo y claves de lectura}

Aunque en el momento de reconstruir o interpretar el paisaje todos los datos a los que nos hemos ido refiriendo son imprescindibles, para este aspecto, en el que ahora vamos a centrarnos, los instrumentos de trabajo específicos son las plasmaciones más directas del paisaje reciente y actual de que disponemos: fotografías aéreas y de satélite y cartografía, junto al trabajo directamente sobre el terreno. Ambos instrumentos nos proporcionan información de diversa índole que permiten análisis cualitativos y cuantitativos, estudios secuenciales (cuando se cuenta con vuelos o mapas de distintas fechas) y temáticos (cartografía específica). En realidad, tanto la fotografía aérea como el mapa son tanto puntos de partida, puesto que proporcionan una información de base, como de llegada, pues en una reelaboración de los mismos puede expresarse una parte importante de los resultados de la investigación.

La fotografía aérea fue considerada desde los últimos años del siglo pásado como un documento útil para la investigación arqueológica (Boni y las tomas sobre el Foro Romano). El éxito de las prospecciones aéreas efectuadas en el período de entreguerras en áreas desérticas 
del Oriente Próximo y Norte de Africa (Poidebard, Baradez) y los pioneros trabajos desarrollados en Europa (Crawford) desde los años veinte, demostraron la riqueza potencial de este material, pero es a partir de los últimos años de la década de los cincuenta cuando gracias a iniciativas como las de Bradford, Schmiedt o Chevallier, su uso se difunde: se empieza a emplear en proyectos de prospección, a sistematizar la forma de trabajo y a sucederse las mejoras técnicas que ampliaban el abanico de posibilidades, desde el uso de películas infrarrojas a la aparición de sofisticadas técnicas de tratamiento de imágenes ${ }^{14}$.

Simultáneamente, ha mejorado y aumentado tanto la cartografía disponible como las posibilidades técnicas de su elaboración ${ }^{15}$ : en especial, gracias a la fotorrestitución los mapas topográficos son más precisos y se han desarrollado importantes series de cartografía temática (mapas geológicos, edafológicos, de usos y cultivos, de series de vegetación, y un largo etcétera). Por otra parte, si la documentación aérea es muy reciente ${ }^{16}$, existe una documentación cartográfica que, en muchos casos, cubre al menos la totalidad de nuestro siglo. En combinación con series de fotogramas de diversas fechas esto posibilita la realización de estudios secuenciales, que pueden resultar muy reveladores ${ }^{17}$.

El estudio morfológico (mediante diferentes métodos) es posible porque en el paisaje actual han quedado elementos del pasado; parte, por lo tanto, de que la actividad humana deja en el paisaje una impronta detectable. Tales elementos aparecen en el paisaje actual de dos formas:

a) como discordancias, anomalías en el paisaje actual

b) integrados en el paisaje actual por uno u otro motivo y cuya antigüedad es detectable de diversas formas (módulos, orientaciones, técnicas, etc.).

La continuidad o desaparición de estos elementos antiguos en el paisaje actual puede responder a muy diversos motivos: pueden ser elementos bien adaptados, «rentables» que han permanecido, pueden ser adaptaciones precarias o coyunturales (en función de una presión demográfica, necesidades defensivas, imposiciones, etc.) o haberse convertido en obstáculos que nunca se han salvado. En cualquier caso, su estudio exige siempre ser considerado en el marco de la historia de ese paisaje.

La posibilidad de detectar estas formas antiguas en el paisaje pasa por la presencia en ellas de una serie de rasgos peculiares que traducen su antigüedad, básicamente se trata de módulos, de métricas en desuso que permiten, por ejemplo, detectar una centuriación romana o cualquier otra división agraria conocida, de orientaciones en discordancia con la o las predominantes, oformas en sí y disposiciones de las mismas, resultado, por ejemplo, de aplicación de determinadas técnicas.

14 Piccarreta, 1987; Sánchez-Palencia-Orejas, 1991.

is Colloque International sur la Cartographie archéologique et historique, Tours, 1972; La cartografia archeologica. Problemi e prospettive, Pisa, 1988.

${ }_{16}$ Para nuestro país, con contadas y aisladas excepciones, no se remonta más allá del año 1956, fecha de realización del llamado «vuelo americano», muy interesante por otra parte ya que recoge la situación de España en el momento inmediatamente anterior a los procesos de expansión urbana, crecimiento industrial y reformas agrarias de la década de los sesenta y posteriores.

17 Como ejemplo de estudios secuenciales a partir de la fotografía aérea: F.-J. Sánchez-Palencia, «El campamento romano de Valdemeda, Manzaneda (León): ocupación militar y explotación aurífera en el NW peninsular», Numantia, 2, 1986 227-235. 
Conforme a esto, podemos concluir que los elementos antiguos en el paisaje actual aparecen de tres formas diferentes:

- elementos fosilizados, que permanecen físicamente más o menos alterados pero sin realizar ninguna función: minas, pólenes, ruinas, tramas de divisiones agrarias, restos de hábitat, roturaciones abandonadas... Precisamente este desuso ha permitido su continuidad en el paisaje, su detección y tipificación (figs. 5 y 6 ).

- elementos reutilizados, que permanecen físicamente con una función diferente (fig. 7) o idéntica (fig. 8) a la que desempeñaron: límites, acequias, caminos, cruces, etc.. que mantienen la memoria de líneas o hitos de una organización anterior del espacio. Pese a esa continuidad, es frecuente que su reconocimiento en el paisaje actual sea difícil, y, a veces, imposible, dada su integración: este es uno de los problemas fundamentales de los trabajos emprendidos en Europa occidental, dada su constante e intensa ocupación a lo largo de la historia, y que ha obligado a recurrir a métodos, como el filtraje óptico. que permita detectar elementos aislados que responden a métricas, orientaciones o formas diacrónicas.

- elementos deducibles por la existencia de indicios: por ejemplo series de elementos que se repiten periódicamente y podemos extrapolar, siempre con enorme precaución (unidades agrarias, tramos de vías perdidos pero reconstruibles a través de la topografía, etc.).

Relacionado con este último tipo de elementos, hay que mencionar que las huellas del pasado en los paisajes actuales son, en ocasiones, irreconocibles porque sus rasgos se han bo-
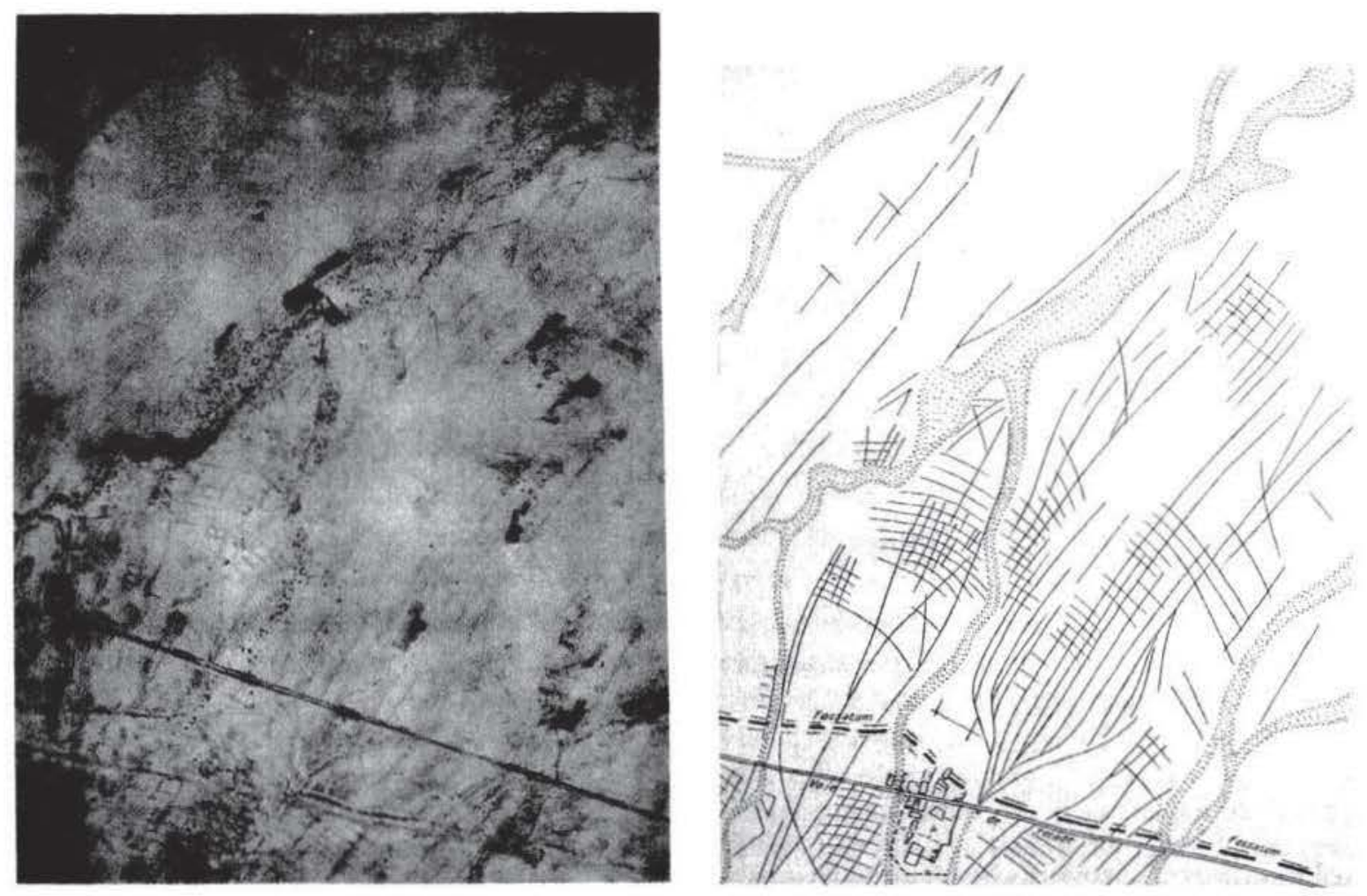

Figura 5,-Paisaje fosilizado. Tabua: fossatum, vía, núcleo agrícola y cultivos irrigados. Fotografía aérea y fotointerpretación de Baradez (Fossatum Africae, 1949). 


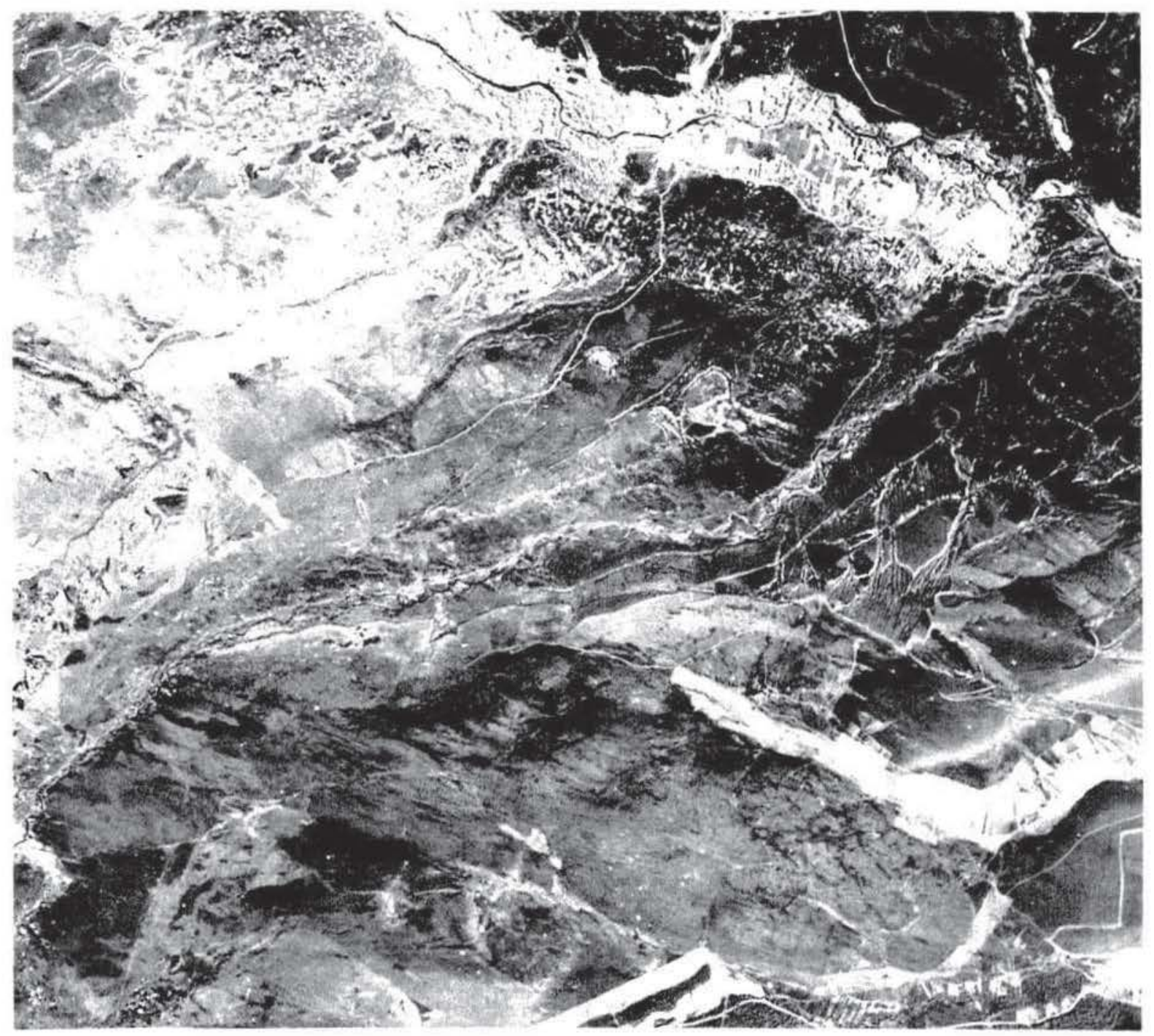

Figura 6.- Paisaje fosilizado. Explotaciones de oro romanas en el valle del río Duerna (León). Fotografía aérea infrarroja.

rrado o confundido totalmente; en otros casos, se detectan de forma aislada o segmentada (por ejemplo exclusivamente los ligados a la actividad agraria). En estas situaciones, la mayoría, en las que no contamos con puntos de partida seguros y tipificados, la opción más adecuada es arrancar del potencial de la zona, de forma que la relación entre los asentamientos reconocidos y las posibilidades del entorno, permita establecer nexos entre ambos. Desde este punto de partida, en ocasiones, se puede precisar más y llegar a poder afirmar la existencia de estos vínculos: por ejemplo, en un primer momento se puede considerar la hipótesis de que un asentamiento o un grupo de ellos exploten un afloramiento rocoso próximo como cantera, si en 
pusteriores procesos de prospección o excavación aparecen restos constructivos de dicho material se puede pasar a afirmar esta relación e incluso la intensidad de la misma (supone pasar de hablar de potencial a territorio de explotación o captación).

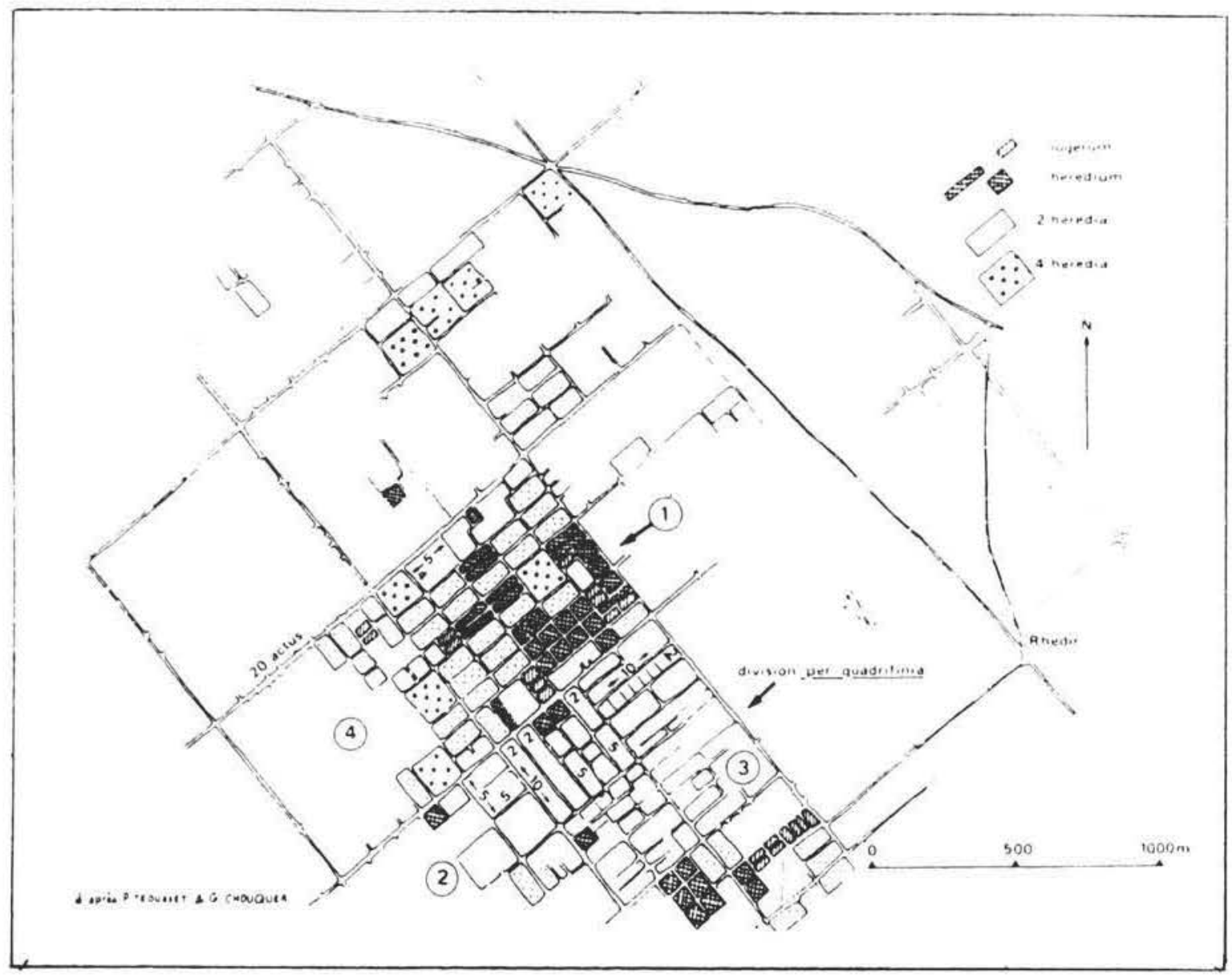

Figura 7.-Elementos reutilizados en el paisaje actual. Una zona del catastro Centro-Este tunecino a partir del análisis de fotografías aéreas realizado por P. Trousset y G. Chouquer. Los antiguos límites de las divisones romanas se han conservado aunque ocasionalmente desarrollaran otra función: caminos, acequias, etc. (F. Favory, «Proposition pour une modélisation des cadastres ruraux antiques», $\mathrm{Ca}$ dastres et espace rural, 1983, 133).

El análisis del potencial es siempre referencial: sin la presencia de elementos claramente detectables no podemos pasar de considerar un área próxima a un hábitat apta para cultivos de secano a afirmar cuantas de esas tierras y cómo se explotaban, sin embargo la presencia/ausencia de recursos en relación con las tecnologías de las diversas comunidades y con cálculos demográficos, es un referente válido para expresar la(s) función(es) de los asentamientos y las relaciones entre ellos.

El análisis de un potencial exige la fijación de una.serie de parámetros para cada uno de los recursos o grupos de recursos considerados, de forma que puedan ser valorados cualitativa 


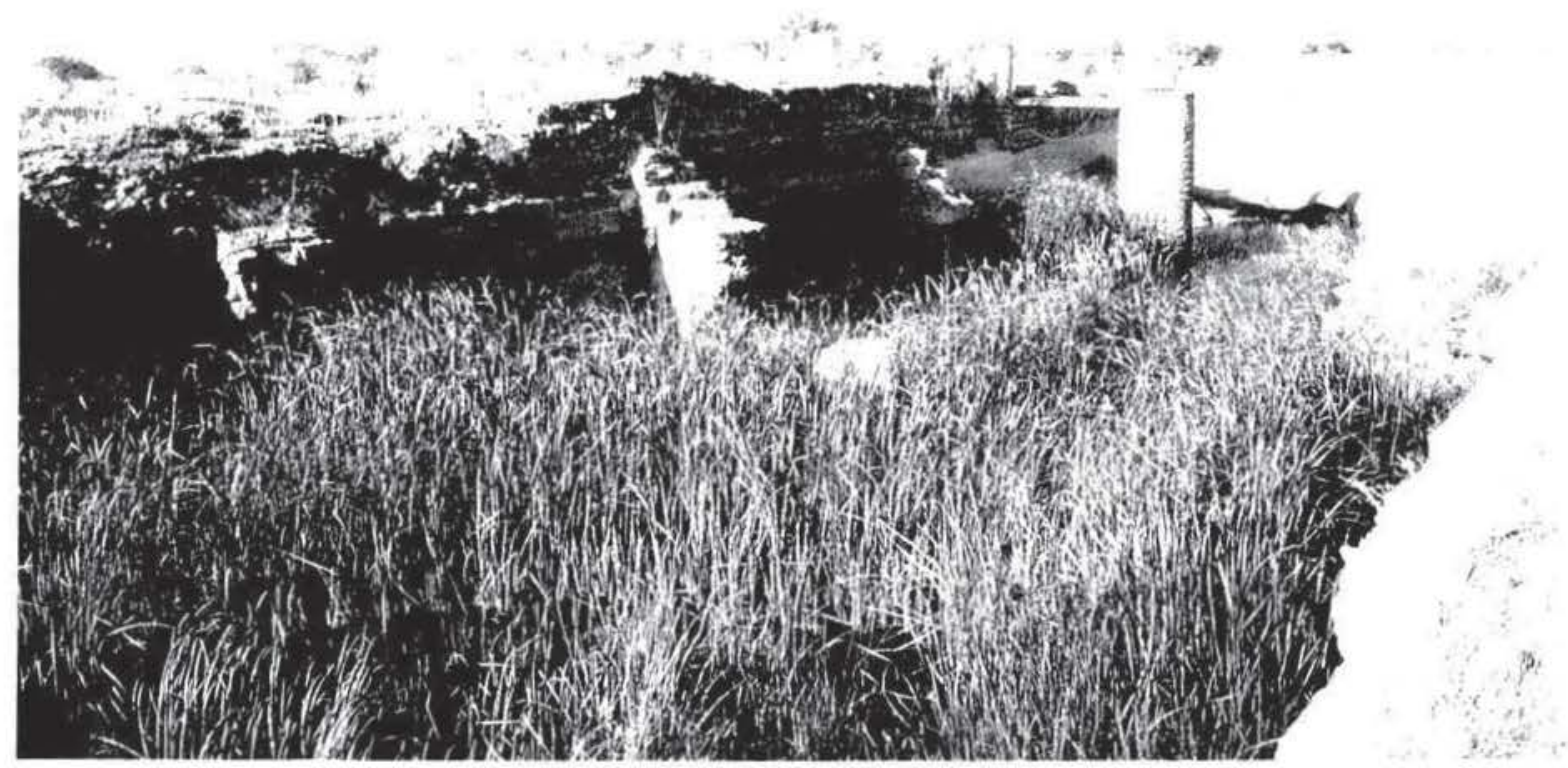

Figura 8. - Elementos reutilizados en el paisaje actual con la misma funcion que desarrollaron en el pasado: presa romana en Casalgordo (Sonseca, Toledo) puesta de nuevo en funcionamiento recientemente.

y cuantitativamente — extensión, volumen, distancia al hábitat, calidad del recurso, elc. - a fin de poder caracterizar la elección de emplazamientos y situaciones y la capacidad de producción de acuerdo con las posibilidades y necesidades de las comunidades.

No se trata de apoyarse en una cartografía actual de recursos (mapas de usos y cultivos, geológicos, etc.), sino de analizar su potencialidad a partir de las condiciones naturales y capacidad de alteración del medio, de ampliar un área de regadío o de explotar un determinado mineral por ejemplo. La referencia de la situación actual, aunque necesaria, puede desfigurar el análisis, en especial en zonas cuya fisonomía ha cambiado drásticamente en las últimas décadas (zonas urbanas, industriales y sometidas a reformas agrarias básicamente).

Así, si la detección de los elementos a los que nos referíamos en primer lugar sólo depende de la capacidad y conocimientos para reconocerlos, la apreciación de los dos últimos exige una aproximación progresiva a nivel individual (singularidades) y a escala global (integración de esos elementos aislados, enmascarados o desaparecidos en una organización a mayor escala): esto implica:

a) trabajar con un considerable volumen de información, en un ámbito espacial amplio y flexible, 
b) transcender constantemente la forma o el conjunto de formas para considerar sus posibles articulaciones a diferentes niveles,

c) reconstruir las líneas de evolución del paisaje, tanto considerando las deformaciones físicas y sus motivos (por ejemplo el paso de una estructura ortogonal en un medio agrario a una radial por la creación de un hábitat central) ${ }^{18}$, como los cambios en la funcionalidad de determinados elementos; es decir, analizar la relación entre innovación y tendencias al estatismo.

El análisis morfológico cubre, así, dos aspectos interdependientes, no sucesivos: el nivel individual, objetual y la articulación de dichos elementos en varios niveles (estructuras intermedias, organización global, etc.); constituye así, una primera aproximación, cualitativa y cuantitativa, al impacto sobre el medio de la actividad humana. la forma no es neutra, y, adecuadamente tratada traduce la organización social, tal y como se expresa en su relación con el medio: descubrirla es tarea de las fases siguientes.

\section{De la detección a la interpretación}

Ya hemos mencionado el riesgo que supone la asunción de correspondencias directas entre elementos formales y funciones. Por ejemplo, la gestión provincial romana, exceptuando casos bien tipificados como la organización del espacio colonial, tiene múltiples plasmaciones que no siguen un modelo único y uniforme: es más, un mismo elemento morfológico puede tener diversas funciones $\mathrm{y}$, a la inversa, el mismo problema se resuelve de maneras diversas: baste recordar el problema de las villae, con morfologías muy variadas y actividades diversas; del mismo modo, no es necesariamente cierto que un parcelario que presente un aspecto fragmentado y heterogéneo se corresponda con una forma de propiedad minifundista.

Con esto queremos advertir sobre el peligro de redactar, exclusivamente a la vista de los resultados del primer nivel de análisis, las conclusiones del trabajo y sobre la necesidad de «manipular» adecuadamente los datos obtenidos. En este «adecuadamente» entran en juego tanto los objetivos planteados en la investigación, como los conocimientos del investigador o equipo y los intereses, de muy diversa índole subyacentes o explícitos (científicos, políticos, económicos...).

El tratamiento de los datos puede ir desde una manipulación gráfica de los mismos (fotorrestituciones, cartogramas combinados, etc.) a la aplicación de tests estadísticos según la problemática planteada, o modelos derivados del análisis locacional, siempre teniendo en cuenta las informaciones obtenidas de otro tipo de datos que mencionamos en los apartados anteriores y cuya integración es ahora imprescindible: aquí es esencial una referencia a las aportaciones de la Arqueología espacial, del SCA y técnicas de cuantificación desarrolladas a partir de la Nueva Arqueología. La elección de la forma e intensidad con que someten los datos a estas diferentes pruebas es, por supuesto, subjetiva, en función de los objetivos del estudio, aunque se puede llegar a una tipificación de las más adecuadas para cada problema; en cualquier caso está en función de la voluntad de obtener una mayor precisión y contrastación de los datos. No se trata de que la realización de un test aporte una mayor certeza a la interpretación global, pero sí permitirá sacar un mayor partido a los datos de que disponemos.

${ }^{18}$ Ver, por ejemplo, Chouquer, 1983. 
Es aquí insoslayable el tradicional problema y falso debate creado en torno a la oposición de los análisis cuantitativos y los cualitativos: no hay que disociar ambas opciones: es inútil negar que hay una apreciación subjetiva, que, además, es el primer acercamiento, la primera impresión — visual - pero, es necesario objetivar, en la medida de lo posible, la información para hacerla comprensible, comparable y evitar los errores de apreciación.

Tres son los problemas fundamentales que plantea esta interpretación de los datos una vez identificados: el establecimiento de una cronología de los paisajes, la validez del "método regresivo" y la existencia de una serie de tópicos de larga tradición. Aún es pronto para poder fijar una cronología del paisaje a partir de su morfología, exceptuando casos muy concretos (por ejemplo módulos de centuriaciones realizadas en épocas determinadas), de leer directamente lo temporal en lo espacial. La forma de abordar el problema es mediante la cronología relativa, basada en las relaciones espaciales que traducen una secuencia temporal entre los diversos elementos detectados en el paisaje: yuxtaposiciones, superposiciones, intersecciones, adaptaciones de unos elementos a otros, nos permiten fijar su relación de anterioridad, simultaneidad o posterioridad y el sentido en que se ham producido los cambios (imposiciones, desusos...). Hábitat, caminos, parcelario, explotaciones mineras, meandros abandonados y colonizados por agricultura, puntos de referencia en redes de comunicaciones, etc., constituyen buenas referencias que proporcionan cronologías relativas entre diversos elementos detectables en el paisaje. Así, la posibilidad de obtener una cronología absoluta para alguno de estos elementos de referencia permite, indirectamente, la datación absoluta de determinado paisaje o de, al menos, una serie de elementos del mismo ${ }^{19}$.

El estudio de los paisajes antiguos, comentaba R. Chevallier en un seminario desarrollado en la Casa de Velázquez en Mayo de $1991^{20}$, plantea un problema filosófico: la posibilidad de ir hacia atrás, lo que Bertrand denominó el «método regresivo». Se trata de saber si parte de unas bases sólidas un estudio que arranca de una situación actual para remontarse hacia el pasado, en ocasiones varios milenios. Efectivamente, en muchos casos hay titubeos, dudas y escepticismos, sin embargo, un avance en esta dirección, aunque parezca lento y costoso, irá sentando las bases de una evolución más rápida, cuando sea posible reconocer e identificar automáticamente determinados elementos morfológicos y su articulación en el espacio y en el tiempo con los restantes.

A la hora de abordar tanto la cuestión de la cronología como la posibilidad de reconocer el pasado en los paisajes del presente, hay que evitar, ante todo, la tentación de pretender hacer un estudio "estratigráfico» del paisaje, buscando, como en una excavación las distintas fases que lo han conformado en un plano «vertical»: si algo caracteriza un estudio de este tipo es la interdependencia del pasado, el presente y el futuro, y su convivencia en el plano «horizontal», por ello no pueden considerarse niveles independientes con la misma relación que tienen entre sí las distintas etapas de ocupación/abandono de un asentamiento con un vacío antes y otro después. El paisaje, solamente puede considerarse - salvo en ocasiones de fosilización absoluta - desde la perspectiva de una continuidad desde el «estado natural» hasta su situación actual y su futuro, al menos inmediato.

${ }^{19}$ Chevallier, 1976, 508; Chouquer, 1990.

${ }^{20}$ Séminaire d'archéologie classique et médievale sous la direction d'André Bazzana. Techniques d'analyse et d'inteprétation, Casa de Velázquez, 6-7 de Mayo 1991. 
El tercer problema que plantea la interpretación de los datos obtenidos tras el análisis morfológico, y una vez identificados, surge de la existencia de una serie de tópicos acerca de los paisajes antiguos, muy difundidos y de los que es necesario deshacerse antes de adentrarse en esta fase. Ideas como la exhuberancia primitiva - ligada a una visión romántica-, la masiva roturación del suelo en época medieval, la asociación exclusiva del paisaje agrario romano a la centuriación, la mitificación de procesos de deforestación y desertización en determinados momentos históricos, la consideración de espacios como improductivos - por ejemplo las tierras altas-, los falsos límites entre suelo habitado/suelo explotado, el fijismo del paisaje antiguo, o, por el contrario su inestabilidad permanente... asumidas como punto de partida pueden falsear radicalmente la lectura de los datos, si no se consideran como hipótesis que se han de contrastar.

\section{IV. ¿ARQueOlogía del PAISAJE, PAISAJE ARQUEOLÓGICO O ARQUEOLOGÍA EN EL PAISAJE?}

A lo largo de los dos últimos siglos se ha roto con la tradicional idea de la naturaleza como algo hostil, como un obstáculo que hay que vencer y del que hay que defenderse. Desde Rousseau o Linneo, pasando por el pensamiento anarquista del siglo XIX (Kropotkin y El apoyo mutuo) y el socialismo utópico hasta llegar a las diversas generaciones de movimientos ecologistas gestados en Europa (Haeckel en Alemania o Lorenz en Austria) y en Estados Unidos (Reich) tanto desde la perspectiva biológica (Haeckel) como desde la economía (Popper-Lynkeus), desde la política (partidos Verdes) o la literatura ${ }^{21}$, la perspectiva en la consideración de las relaciones del hombre con la naturaleza ha cambiado radicalmente: la naturaleza ha dejado de ser un enemigo, el control sobre ella crece en progresión geométrica y paralelamente surge la conciencia de su destrucción irreversible.

Este cambio, agudizado en nuestros días, responde a múltiples tensiones y de muy diversa índole: políticas, sociales, económicas, científicas, incluso éticas (figura 2). Toda esta serie de cuestiones ha provocado, una alteración del concepto de patrimonio, en el que lo natural y lo social o lo histórico-social, tienden a considerarse de una forma conjunta ante la imposibilidad de disociarlos, al confirmar que lo natural en estado puro no existe. La reivindicación de la Amazonia es hoy por hoy, una muestra del interés que despiertan estos «paisajes residuales» que se protegen por estética y por su interés científico tanto como por economía, política o propaganda ${ }^{22}$.

La situación generada por la escasez de espacio y recursos —en realidad habría que hablar de mala distribución mejor que de escasez - ha dado lugar a respuestas variadas que van desde la especulación a la planificación, pero, sobre todo, ha creado una receptividad especial hacia este tipo de problemas. La ciencia no se ha quedado al margen de todo ello y han sur-

21 Bramwell, 1989.

${ }^{22}$ Esta nueva visión del patrimonio está ya, de hecho, recogida en la legislación, tal y como propone el apartado 1 del artículo 40 de la Ley del Patrimonio Histórico Español de 1989: «... forman parte del Patrimonio Histórico Español los bienes muebles e inmuebles de carácter histórico susceptibles de ser estudiados con metodología arqueológica, hayan sido o no extraídos y tanto si se encuentran en la superficie o en el subsuelo, en el mar territorial o en la plataforma continental. Forman parte, asimismo, de este patrimonio, los elementos geológicos y paleontológicos relacionados con la historia del hombre y sus orígenes y antecedentes». 
gido, mencionando dos casos claros, desde el campo de la Biología especialistas en estudios de impacto ambiental o de la Geografía proyectos de planificación territorial.

Ya hemos revisado cómo desde los años sesenta la Historia y la Arqueología empezaron, aunque en ámbitos muy reducidos, a hacerse eco de estas inquietudes, en especial a través de las diversas aproximaciones ecológicas; sin embargo, es necesaria una toma de conciencia tanto del papel que estas ciencias pueden jugar en este terreno como de la nueva consideración del patrimonio histórico no como algo aislado en el tiempo y el espacio, lo que conlleva la formación de arqueólogos e historiadores en este terreno.

\section{Las posibilidades y los risgos científicos}

Ya hemos repetido que esta situación nace de una evolución interna de las ciencias - bloqueo de vías de investigación, nuevas posibilidades técnicas, etc.- en ningún caso desligada de unas demandas sociales. La aceptación de la necesidad de un cambio desde esta doble presión pasa por una serie de exigencias, abre nuevas perspectivas, pero también plantea unos riesgos.

Efectivamente, la escala de la investigación arqueológica cambia de una forma clara: se hace necesaria la superación de los tradicionales esquemas tipológicos, cronológios y espaciales cerrados y la elaboración de estrategias generales de investigación, de bases teóricas y metodológicas que se integren en marcos más amplios de intereses interdisciplinares y sociales. Esto implica acabar con la sima que progresivamente se ha ido abriendo entre la Historia y la Arqueología y la sociedad, y que ha provocado una radical «deshumanización» de las llamadas Humanidades, su ruptura con las Ciencias Sociales y una creciente disociación de intereses, apoyándose en un absurdo elitismo que ha dado lugar, exclusivamente, a un aislamiento y mutuo recelo.

Esta reconciliación no implica, como algunos pretenden, una pérdida de calidad en la investigación limitada a una labor de divulgación, por otra parte necesaria, sino una radical renovación.

Sin embargo, se abren nuevos riesgos y se replantean, desde otro ángulo, peligros antiguos entre los que es especialmente evidente el del localismo: es evidente que el estudio a escala regional o local es necesario, pero siempre y cuando nazca y tienda a una perspectiva global: el mundo no está compuesto en un momento dado, por minúsculas unidades que funcionan espacialmente aisladas a ritmos y escalas diferentes. En segundo lugar hay que evitar el rechazo visceral a la «arqueología tradicional»: superarla no significa no reconocer que gracias a sus avances es posible un replanteamiento. Por último, queda señalar lo que podríamos denominar como la «tentación de la tecnificación», es decir, la formación de arqueólogos especialistas en la aplicación de determinadas técnicas pero que pierdan la perspectiva en que se han de inscribir sus resultados, de la integración y la interpretación.

\section{¿Arqueología del paisaje, paisaje arqueológico o arqueología en el paisaje?}

La oposición no es un mero juego de palabras, intenta resumir las opciones que se le presentan al arqueólogo en el momento de integrar el paisaje no ya en su investigación, sino den- 
tro del patrimonio social: la vertiente investigadora y los planteamientos ligados a la «socialización" están - deben estar- estrechamente ligados: de las líneas que rigen el estudio se deriva una forma de presentarlo, difundirlo e integrarlo en la sociedad.

La Arqueología del paisaje, tal y como la hemos planteado se opone al paisaje arqueológico que transmite una visión estática, una especie de museo al aire libre que no hace sino reproducir la misma idea que tradicionalmente ha regido la visita a ruinas y museos; del mismo modo con la expresión «arqueología en el paisaje» nos referimos a la presencia en el paisaje actual de elementos singulares del pasado, hitos descontextualizados, asociados, por regla general, a lo monumental.

Por el contrario, se propone un trabajo basado en la integración de elementos en el espacio y en el tiempo, opuesta a visiones estáticas y contemplativas, capaz de leer en la forma en la que se han plasmado las relaciones del hombre con su entorno no sólo dietas o densidad demográfica, sino tradiciones, la valoración del riesgo, relaciones entre comunidades, etc.

Desde el momento en que se reconoce la presencia de elementos de un paisaje antiguo se plantea, como cuando se detecta un yacimiento arqueológico, el problema de qué hacer con ello: se trata, en muchas ocasiones, de elementos sin función o destinados a carecer de ella en breve plazo. En muchos casos la cuestión no es fácil: no es, con frecuencia, posible respetar esas huellas del pasado e integrarlas en la configuración real y mental del paisaje actual, en otros casos, una planificación adecuada puede conseguir no sólo que esos rasgos sean respetados, sino que además contribuyan a dinamizar el paisaje del presente y a una revalorización de las relaciones del hombre con su entorno, como recurso y reflejo de su historia, como patrimonio común.

Conocer y documentar el pasado y el presente significa tener la posibilidad de superarlo, no fosilizarlo, bloquearlo o convertirlo en una reliquia descontextualizada. En el marco de las exigencias sociales, el paisaje del pasado puede encontrar una vía de expresión en los proyectos de parques arqueológicos, concebidos a la raíz de la creación de parques naturales, recogiendo esta reivindicación del patrimonio común, de las necesidades generadas por el ocio, de la recuperación de espacios y formas de vida extinguidas o en proceso de desaparición, y entendidos como proyectos que exigen una adecuada investigación y gestión. No se trata de emprender la creación de una especie de zonas recreativas, sino de saber «actualizar» el pasado, hacerlo accesible, desmitificarlo, contextualizarlo y reconocerlo. Preservación y difusión no son sinónimos de fosilización y comercialización.

La Arqueología tiene algo que decir en los procesos de racionalización y planificación del espacio, no sólo para llamar la atención sobre los restos de asentamientos antiguos que salpican ese espacio y que hay que respetar en la medida de lo posible y documentar, sino para convertirse en elemento integrador y dinamizador de ese espacio.

\section{BIBLIOGRAFÍA}

\section{La formación de la Arqueología del paisaje}

Agache, R., La Somme pré-romaine. Amiens, 1978.

Aston, M.-Rowley, T., Landscape Archaeology. An Introduction to Fieldwork Techniques on PostRoman Landscapes, Londres, 1974. 
Baradez., J., Vue aériène de l'organisation romaine dans le Sud-Algérien. Fossatum Africae. París. 1949.

BERESFORD, M.-HuRst, J., Wharram Percy. Deserted Medieval Village. Londres, 1990.

BERTRAND, G.. «Pour une histoire écologique de la France rurale». Histoire de la France rurale ( $G$. Duby-A. Wallon eds.). I, 1975, 34-113.

Bertrand, G., "Le paysage entre la nature et la societé», Rèue Geographique des Pyrénées el du Sud Quest. 49, 1978a, 239-258.

BERTRAND, G., "L"“Archéologie du paysage" dans la perspective de l'écologie historique», Actes du colloque Archéologie du paysage. Paris, Mai 1977. Caesarodumum. 13, 1978b. 132-138.

BINFORD, S.-BINFORD, L. (EDS.), New perspectives in Archaeology: Nuevat York, 1968.

BLoCH, M., Les caractères originaur de l'histoire rurale fransaise, 2 vols., París. 1952-56.

Bloch, M., L'histoire rurale fransaise. París, 1961-64.

Bowen, H. C.-Cunl.iffE, B., «The Society Research Projects: The Evolution of the Landscape», The Antiquaries Jorunal, 53, 1973, 9-13.

BRADFORD, J. S. P., "Etrurian from the Air», Antiquity, 21, 1947, 74-83.

BRADFORD, J. S. P., Ancient Landscapes. Studies in Field Archacology. Londres, 1957.

BRANWELL. A., Ecology in the 20th century: a History, 1989.

Brongers, J. A., Air photography and celtic fields research in the Netherlands, Amersfoort, 1976.

CAillemer, A.-Chevallier, R., Atlas des centuriations romaines de Tunisie, París, 1956.

CAStagnol, F., "Contributi della fotografia aerea agli studi di Topografia Antica in Italia", Atti del Settimo Congresso Internazionale di Archeologia Classica, I, Roma, 1961, 41-45.

ChORley, R. J.-HagGett, P. H., Models in Geography, Londres, 1967.

Clark, G., Prehistoric Europe: the Economic Basis, 1952.

Clarke, D. L., Analytical Archaeology, Londres, 1968.

ClARKE, D. L. (ED.), Models in Archaeology. Londres, 1972.

ClARKE, D. L., «Archaeology: the loss of inocence», Antiquity, 47. 1973, 6-18.

CLARKE, D. L. (ED.), Spatial Archaeology, Cambridge, 1977.

CRAWFORD, O. G. S. C.-KEILler, A., Wessex from the Air, Oxford, 1928.

Deleage, A., Les cadastres antiques jusqu'à Diocletien, Etudes de Papyrologie, 2, 1934, 73-228.

DiON, R., Essai sur la formation du paysage rural francais, Tours, 1934.

DUfournet, P., «Archéologie du sol: une méthode pour remonter le temps basée sur l'analyse graphique du cadastre savoyard (1730)», Colloque International sur la Cartographie archéologique et historique, Tours, 1972, 51-59.

FebVRE, L., La Terre et l'évolution, París, 1922.

FERNANDEZ MIRANDA, M., «Entre la antropología y la historia», Revista de Occidente, 81, 1988, 5-14.

FlanNery, K. V.-COE, M. D., «Social and Economic Systems in Formative Mesoamerica» New' Pespectives in Archaeology (Binford-Binford eds.). Chicago, 1969, 267-284.

FOCHLER-Hauke, Géographie, 1959.

FOWLER, P. J., Archaeology and the Landscape. Essays for L. V. Grinsell, Londres, 1972.

FREMONT, A., «Les profondeurs du paysage géographique», L'Espace Géographique, 3, 1974, $127-136$.

GALLOIS, L., Régions naturelles et noms de pays, París, 1908.

Gould, P. R.-White, R., Mental maps, 1974.

Haggett, P., Locational Analysis in Human Geography, Londres, 1965.

Hodder, I.-Orton, C., Spatial analysis in Archaeology, Cambridge, 1976.

Hoskins, W. G., The Making of the English Landscape, Londres, 1955.

Jankuhn, H., Archäologie und Geschichte. Band I, Berlin, 1976.

JARMAN, M. R., «A territorial model for archaeology: a Behavioural and geographicla approach», M()dels in Archaeology (D. L. Clark, ed.) Londres, 1972, 705-733.

LUGLI, G., «L'impòrtanza del rilievo aereo negli studi di topografia archeologica», Atti del V Congresso Nazionale di Studi Romani, II, Roma, 1940, 143ss. 
Lrvell. La imagen de la ciudad. 1970.

PoIDF BARID. A.. La trace de Rome dans le désert de Syrie. Le limes de Trajan à la conquête arabe. Recherches aériennes (1925-19.32), París. 1934.

RATZEI. F., «Le sol, la societé el t'état". L'Année Sociologique, 3, 1898-99, 1-14.

SCHAEF:R, F., "Excepcionalism in Geography», Annals of Association of American Geographers, 43, 1953. 226-249.

S(HmiEDT, G.. Altante Aerofotograficon delle Sedi Umane en Italia.vol. II Florencia, 1970); vol. III. Florencia. 1990.

SCHMIEDT, G.-CHEVAlLIER, R., Caulonia e Metaponto. Applicazioni della fotografia aerea in recerche di topegrafia antica nella Magna Grecia. Florencia, 1959.

SERENI, E.. Comunità rurali nell'Italia antica. Roma, 1955.

SERENI, E., Histoire du paysage rural italien, París, 1965.

SERENI. E., "Villes et campagnes dans L'Italie préromaine», Annales ESC, 1967, 23-49.

StEENSBERG, A., Atlas over Bosupsagre, Copenhague, 1968.

Tuan, Y. F., Topophilia. A Study of Environment Perception. Attitudes and Values, Nueva York, 1974.

VIDAL DE LA BLACHE, P., «Tableau Géographique de France», Histoire de France (E. Lavisse ed.), I, París, 1905.

VIDAL DE LA BLACHE, P., Principes de Géographie humaine (recopilados por E. de Martonne), París, 1922.

Vita FinZI, C.-Higgs, E., «Prehistoric Economy in the Mount Carmel Area of Palestina: Site-Catchment Analysis», Proceedings of the Prehistoric Society, 36, 1970, 1-37.

WILL.EY, G. R., Prehistoric Settlement Pattern in the Virú Valley, Peru, Washington, 1956.

\section{El paisaje en la Arqueología hoy}

ARQUEOLOGIA ESPACIAL., Arqueología Espacial. Coloquio sobre distribución y relaciones entre asentamientos, 1-6, Teruel, 1984-85.

ARQueOlogia esPaCial.., Arqueología Espacial, Coloquio sobre el microespacio, 7-10, Teruel, 1986.

Bazzana, A.-Humbert, A., Prospections aériennes: les paysages et leur histoire. Cinq campagnes de la Casa de Velázquez en Espagne (1978-1982), París, 1983.

BIGET, J. L.-HERVE, C.-THEBERT, Y. (EDS.), Les cadastres anciens des villes et leur traitement par l'informatique (Table Ronde, 1985), Roma, 1989.

BIRKS, H. H.-BIRKS, H. J. B.-Kaland, P. E.-MoE, D. (EDS.), The Cultural Landscape. Past, Present and Future, Cambridge, 1988 (con una amplia bibliografía).

BUTZER, K., Archeology as human Ecology. Method and theory for a contextual approach, Cambridge, 1983.

CADASTRES ET ESPACE RURAL, Cadastres et espace rural. Table Ronde de Besanson (Besançon, Mai 1980), París, 1983.

CAMBI, F. P., «Carte diacroniche degli insediamenti: alcuni esempi», La Cartografía Archeologica. Problemi e prospetive. Atti del Convegno Internazionale (Pisa, 21 -22 Marzo 1988), Pisa, 1989, 217-227.

ChOUQUER, G.-FAVORY, F., «Un outil pour l'analyse des paysages et la recherche de structures antiques: la filtrage optique des photographies aériennes», Revue d'Archéologie, 5, 1981, 41-60.

Clavel-Leveque, M., «Pratiques impérialiste et implantations cadastrales», Ktema, 8, 1983, 185-251.

Criado Boado, F.-AIRA Rodriguez, M.a J.-DiaZ-Fierros, F., La construcción del paisaje: megalitismo y ecología. Sierra de Barbanza, Santiago de Compostela, 1986.

CUCINI, C.-GUIDERI, S.-PAOLUCCI, G.-VALENTI, M., «Proposte per una lettura ragionata delle emergenze in elevato e in superficie sul territorio", La Cartografia Archeologica. Problemi e prospetive. Atti del-Convegno Internazionale (Pisa, 21-22 Marzo 1988), Pisa, 1989, 53-101. 
Fronteras, Fronteras. Arqueología Espacial. 13, Teruel, 1989.

HODDER, I., "New generations of spatial analysis in Archaeology". Arqueología Espacial, 1, Teruel. 1984, 7-24.

HODDER, 1., "Postprocesual Archaeology", Advances in Archaeological Theory and Method (M. Schiffer ed.), 1985, 1-23.

HODDER, I., «La Arqueología en la época postmoderna», Trabajos de Prehistoria, 44, 1987, 11-26.

HODDER, I., Interpretación en Arqueología. Corrientes actuales. Barcelona, 1988.

LEY. D., Geography without Man. A Humanistic Critique. Oxford. 1980.

MISURARE LA TERRA, Misurare la terra: centuriazione e coloni nel monde) romano. Roma, 1984.

PEET, R., Radical Geography. Alternative viewpoints on contemporary social issures, Londres, 1977.

PLANA MALlaRT, R., Morfologia històrica del territori del Nordest Català durant lés èpoques pre-romana i romana. Tesis doctoral inédita, Barcelona, 1990.

\section{Fotointerpretación, teledetección y cartografía}

ARCHEOlogie Aerienne, Colloque International d'Archéologie Aérienne (31 Aout-3 Septembre 1963), París, 1964.

Cartografia Archeologica, La Cartografia Archeologica. Problemi e prospetive. Atti del Convegno Internazionale (Pisa. 21-22 Marzo 1988). Pisa, 1989.

CHEVAlLIER, R., L'avion à la découverte du passé, Paris, 1964.

CHEVALLIER, R.,La photographie aérienne, París, 1971.

CHEVAllier, R. (ED.), Colloque International sur la Cartographie Archéologique et Historique. París. 24-26 Janvier 1970, 2 vols., Tours, 1972.

CHUVIECO, E., Fundamentos de teledetección espacial, Madrid, 1990.

DASSIE, J., Manuel d'Archéologie aérienne, París, 1978.

PicCARRETA, F., Manuale di fotografia aerea. L'uso archeologico. Roma, 1987.

Prospection Archeologique, La prospection archéologique. Paysage et peuplement (Documents d'Archéologie Française, 3), París, 1986.

SABATE, A., "Fotointerpretación y tendencias recientes en Geografía Humana», Teoría y Práctica en Geografía, Madrid, 1986.

SANChez PalenCia, F. J.-OReJas, A., «Fotointerpretación arqueológica: el estudio del territorio». Nuevas Tendencias. Arqueología, Madrid, 1991, 1-22.

Spectal Archeologie Aerienne, Spécial Archéologie Aérienne, Dossiers de l'Archéologie, 22, 1977.

Teledetection et CaRTographie, Télédétection et cartographie thématique en Archéologie. París, 1988.

WILSON, D. R., Air Photointerpretation for archaeologists, Londres, 1982.

\section{El paisaje como objeto de estudio: la ciencia del paisaje. Síntesis y perspectivas}

AGACHE, R., «L'archéologie des paysages disparus». Dossiers d'Archéologie, 43, 1980, 19-23.

ARCHAEOLOGY AND THE LANDSCAPE, Archaeology and the Landscape, Londres, 1972.

ARCHEOLOGIE DU PAYSAGe, Actes du colloque Archéologie du paysage (París, Mayo 1977). Caesarodunum, 13, 1978 (con abundantes referencias bibliográficas hasta la fecha del congreso).

BARCELO, M., "La Arqueología extensiva y el estudio de la creación del espacio rural», Arqueología Medieval. En las afueras del "medievalismo» (M. Barceló et alii), Barcelona, 1988, 195-274.

Blanchemanche, Ph., Bâtisseurs de paysages, Paris, 1990.

BOIS ET FORET, Le bois et la foret en Gaule et dans les provinces voisines. Actes de Colloque. Caesarodunum, 21, 1985. 
CHAPt:Lot. J.. "L'étude des territories fossiles. Orientations méthodologiques et résultats récents de l'archéologie médievale en Europe du Nord-Quest». Actes du Colloque Archéologie du Paysage. (Puris. Ens. Mai 1972). Caesarodunum. 13, 1978. 396-419.

Chivali.II:R, R., "Cité et territoire. Solutions romaines aux problèmes de l'organisation de l'espace. Problèmatique 1948-1973», ANRW. II. 1. 1974, 649-788.

Chivalt.lFR, R., "Le paysage palimpseste de l'histoire. Pour une archéologie du paysage», Mélanges de la Casa de lélázque: $12.1976,503-510$.

Ciotquer. G., "Dégradation et fossilisation des cadastrese centuriés. Etude morphologique». Cadastres et espace rural, Paris, 1983, 137-157.

Chovquer, G., Cours d'archéomorphogie. Carto-Interpretation. Photointerpétution, Besançon, 1990.

Chouquer, G.-FAvory, F.. Parsages et cadastres de l'Occide'nt romain. (en prensa).

FRANCOVICH, R., «Archeologia postclassica e restauro: dalle stratigrafia del sottosuolo alla stratigrafia del sopravissuto", Anastilosi. L'antico, il restuaro e la città. Bari, 1987, 251-257.

GEORGE, P. «La géographie, histoire profonde. A la recherche d'une notion globale de l'espace», Annales de Géographie. 498, 1981, 203-210.

GuILAINE, J. (ED.), Pour une Archéologie Agraire, Paris, 1991 (detallada bibliografía ordenada por temas).

KURT, W., Arqueología y paisaje, Cáceres, 1988.

LEACH, E., The rethoric of space. Literary and artistic representations of landscape in republican and augustan Rome. 1988.

Lizet, B.-RAVIGnAN, F. DE. Comprendre un apysage. Guide pratique de recherche, Paris, 1987.

MARCEL, O. (Dir.), Composer le Paysage. Constructions et crise de l'espace (1789-1992), Seyssel, 1989.

PERFL.MAN, R., "L'archéologie dans la problématique générale des paysages», Actes du Colloque Archéologie du Paysage. Paris. Ens. Mai 1972. Caesarodunum, 13, 1978, 571-577.

QuAINI, M., "Storia, Geografia e Territorio. Sulla natura, gli scopi e i metodi della geografia storica», Miscellanea Storica Ligure, 6, 1974, 7-102.

RENFREW, C.-BAHN, P., Archaeology: Theories. Methods and Practice. 1991.

SGARD, J., «Exemples concrets d'intégration de données paysagères dans le processus d'aménagement régional», Actes du Colloque Archéologie du Paysage. Paris. Ens. Mai 1972. Caesarodunum, 13, $1978,565-569$.

TAILLEFER, F., "La science du paysage», La pensée géographique fransaise contemporaine, Rennes. 1972.

UCKo, J.-Trinham, R.-Dimbleby, Q. W., Man, Settlement and Urbanism, Londres, 1972.

VALI.AT, J. P., «De la prospection à la synthèse d'histoire rurale. Documents de la recherche et problèmes d'interpretation", Actualité de l'Antiquité. Actes du colloque organisé à l'université de TolouseLe Mirail par la revue Pallas. Décembre 1985. Toulouse, 1989, 101-127.

Vil.LeS ET CAMPAGNES, Villes et campagnes dans l'Empire romain. Actes du Colloque organisé à Aixen-Provence par l'UER d'Histoire. Aix-en-Provence, 1982. 